\title{
Progress Report on a Fully Automatic Gas Tungsten Arc Welding (GTAW) System Development
}

\author{
G. J. Daumeyer III
}

KCP-613-4884

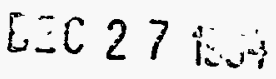

OSTI

Published December 1994

Topical Report

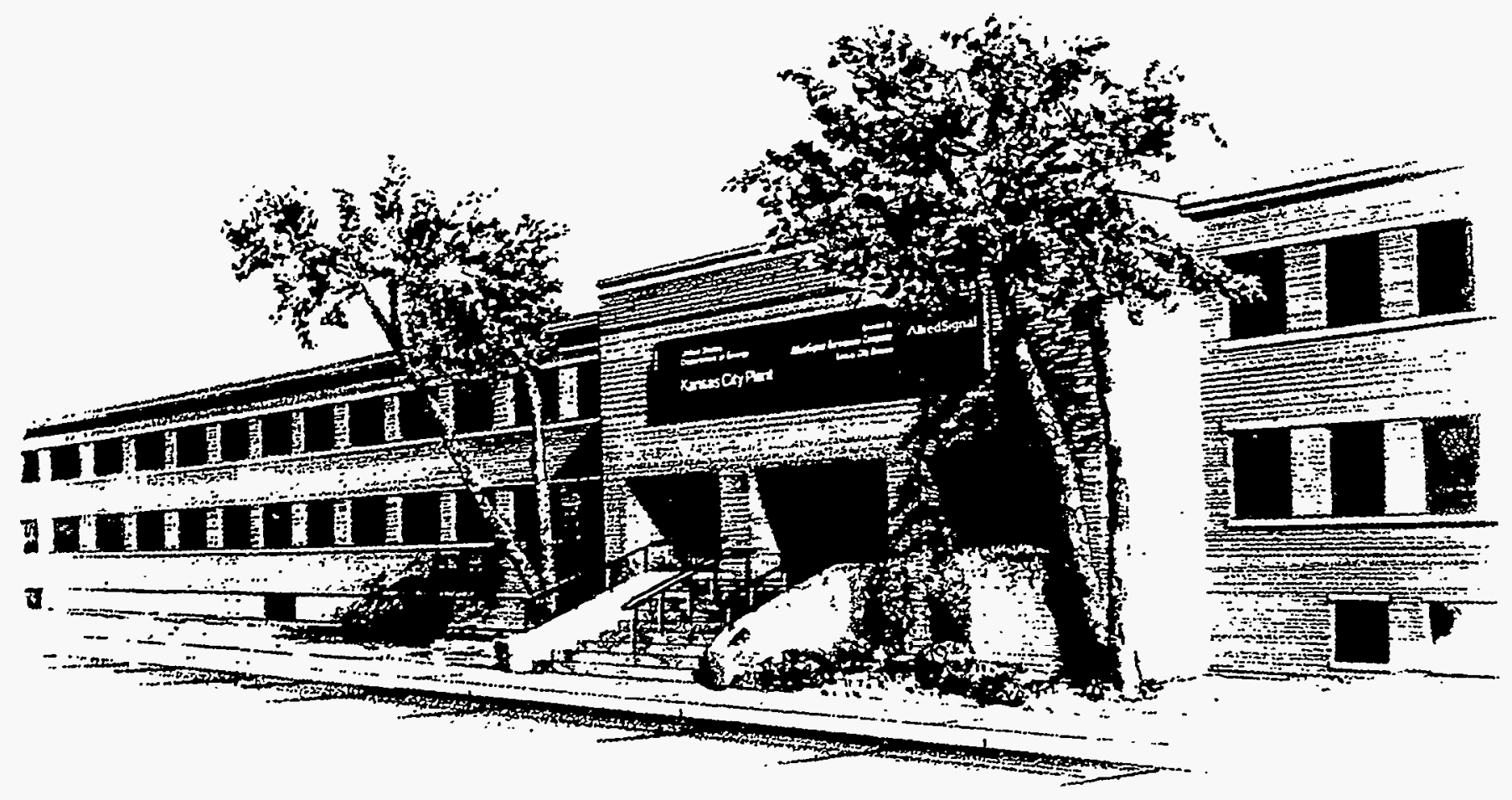

Prepared Under Contract Number DE-ACO4-76-DP00613 for the United States Department of Energy

AlliedSignal

A E R OS PACE

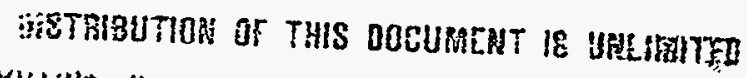

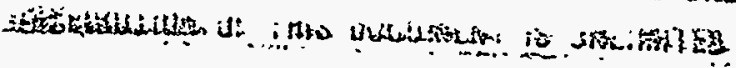




\section{DISCLAIMER}

This report was prepared as an account of work sponsored by an agency of the United States Government. Neither the United States Government nor any agency thereof, nor any of their employees, makes any warranty, express or implied, or assumes any legal liability or responsibility for the accuracy, completeness, or usefulness of any information, apparatus, product, or process disclosed, or represents that its use would not infringe privately owned rights. Reference herein to any specific commercial product, process, or service by trade name, trademark, manufacturer, or otherwise, does not necessarily constitute or imply its endorsement, recommendation, or favoring by the United States Government or any agency thereof. The views and opinions of authors expressed herein do not necessarily state or reflect those of the United States Government or any agency thereof.

Printed in the United States of America.

This report has been reproduced from the best available copy.

Available to DOE and DOE contractors from the Office of Scientific and Technical Information, P. O. Box 62, Oak Ridge, Tennessee 37831; prices available from (615) 576-8401, FTS 626-8401.

Available to the public from the National Technical Information Service, U. S. Department of Commerce, 5285 Port Royal Rd., Springfield, Virginia 22161.

A prime contractor with the United States Department of Energy under Contract Number DE-ACO4-76-DP00613.
AlliedSignal Inc. Kansas City Division P.O. Box 419159 Kansas Clty, Missouri 64141-6159 


\section{DISCLAIMER}

Portions of this document may be illegible in electronic image products. Images are produced from the best available original document. 
KCP-613-4884

Distribution Category UC-706

Approved for public release; distribution is unlimited.

\title{
PROGRESS REPORT ON A FULLY AUTOMATIC GAS TUNGSTEN ARC WELDING (GTAW) SYSTEM DEVELOPMENT
}

\author{
G. J. Daumeyer III \\ Published December 1994 \\ Topical Report \\ G. J. Daumeyer III, Project Leader \\ Project Team: \\ J. P. Dereskiewicz \\ D. L. Hollar, Jr. \\ A. W. Robbins
}

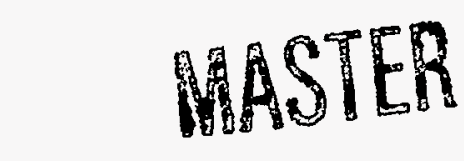

AlliedSignal 


\section{Contents}

Section Page

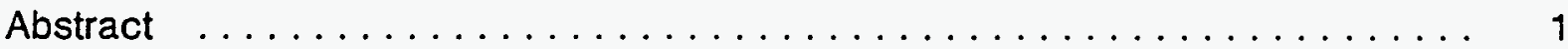

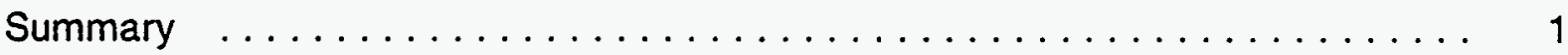

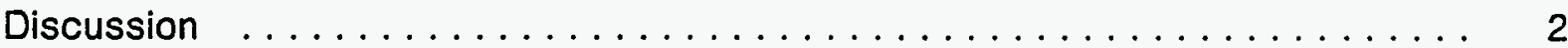

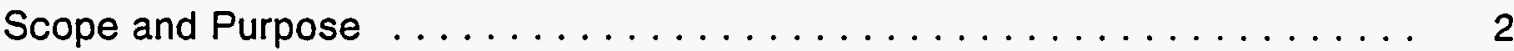

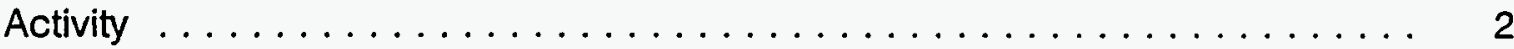

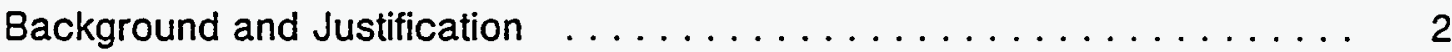

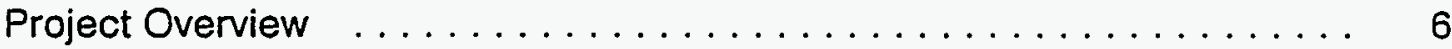

Literature Search Summary $\ldots \ldots \ldots \ldots \ldots \ldots \ldots \ldots \ldots \ldots$

Vision-Sensor Torch Development $\ldots \ldots \ldots \ldots \ldots \ldots \ldots \ldots \ldots$

Data Acquisition and Statistical Analysis System Development . . . . . . 19

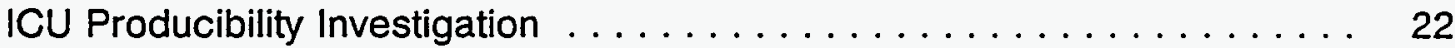

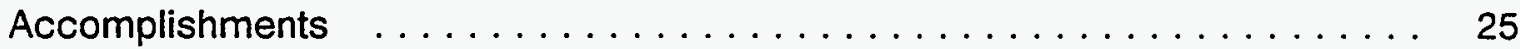

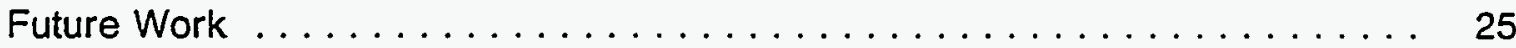

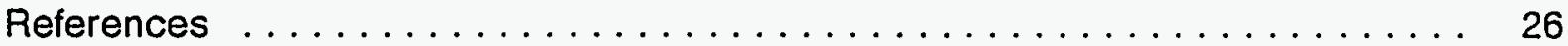

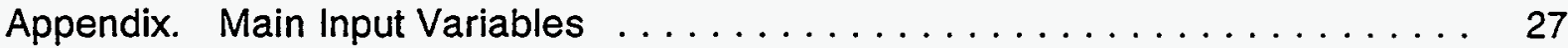




\section{Illustrations}

Figure

Page

1 Weld Joint Geometry variables $\ldots \ldots \ldots \ldots \ldots \ldots \ldots$

2 Worst Case of the Weldment $\ldots \ldots \ldots \ldots \ldots \ldots \ldots \ldots$

3 Joint Tracking Four Ways $\ldots \ldots \ldots \ldots \ldots \ldots \ldots \ldots \ldots$

4 Device Reliability and Information Gained From Each $\ldots \ldots \ldots \ldots$

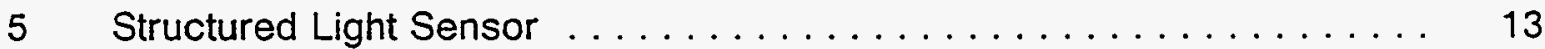

$6 \quad$ Argon Arc Spectrum Showing the $780 \mathrm{~nm}$ Wavelength Opening . . . . . 14

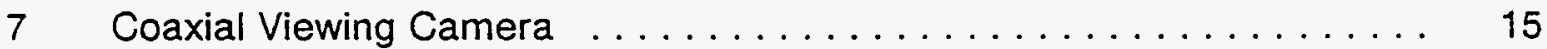

8 Development Coaxial View Welding Torch $\ldots \ldots \ldots \ldots \ldots \ldots$

$9 \quad$ Monitor View From the Coaxial Camera . . . . . . . . . . . . . . . 16

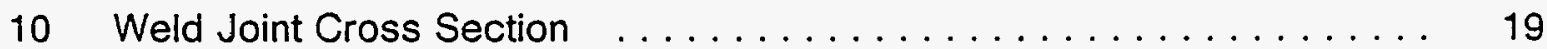

11 ICU Connectors and Cover With Welding Torch $\ldots \ldots \ldots 23$

\section{Tables}

Number

Page

1 Weld Schedule Variables $\ldots \ldots \ldots \ldots \ldots \ldots \ldots \ldots \ldots$

2 Manual GTAW Process Sensors Information and Use . . . . . . . . . 10

$3 \quad$ Feature Detected and Device to Use $\ldots \ldots \ldots \ldots \ldots \ldots$

4 Weld Joint Features and Tolerances $\ldots \ldots \ldots \ldots \ldots$

$5 \quad$ Gas Shielding Methods . . . . . . . . . . . . . . . . . . . . 24 


\section{Abstract}

A plan to develop a fully automatic gas tungsten arc welding (GTAW) system that will utilize a vision-sensing computer (which will provide in-process feedback control) is presently in work. Evaluations of different technological aspects and system design requirements continue. This report summarizes major activities in the plan's successful progress. The technological feasibility of producing the fully automated GTAW system has been proven. The goal of this process development project is to provide a productionready system within the shortest reasonable time frame.

\section{Summary}

This report describes the past activities of a process development project on a fully automatic gas tungsten arc welding (GTAW) system. This GTAW system is to have in-process feedback control from a vision-sensing computer. The past activities are described in four areas: (1) a literature search summary, (2) the visionsensor torch development, (3) the data acquisition and statistical analysis system, and (4) the Inner Connect Unit (ICU) producibility investigation.

The project is approximately $50 \%$ complete. The primary objective is to increase process control over GTAW by using state-of-the-art technologies proven in research labs and universities.
Secondary objectives are to decrease the cost of nonconformance in the welding operations and possibly relax machining tolerances in the machining operations.

By using a vision-sensing GTAW torch (described later), it is possible to gain video images of the weld joint geometry and the weld joint location. By using specialized computer boards, vision processing and data acquisition will be performed in order to provide closed loop feedback control. It is the intent that the design of this fully automatic GTAW system apply to present and future GTAW welded product at AlliedSignal Inc., Kansas City Division (KCD). 


\section{Discussion}

\section{Scope and Purpose}

The purpose of this report is to generally describe the past activities completed on the fully automatic gas tungsten arc welding (GTAW) system development and to explain the direction of work yet to be completed.

The purpose of these activities is to develop a GTAW system that will utilize a visionsensing computer which will provide feedback process control. The following activities are included in this project.

1. Literature search summary and report.

2. Vision-sensor torch development.

3. Data acquisition and statistical analysis system development.

4. ICU producibility investigation.

\section{Activity}

\section{Background and Justification}

The reasons for developing a vision-sensing fully automatic GTAW system are diverse and complex. The goal of this development project is to have a system that eliminates most of the recognized difficulties in the present KCD production methods. Listed below are five reasons to develop a completely automatic GTAW system.

1. Complete process control.

2. Path finding and tracking.

3. Reduction of inappropriate welding.
4. Weld Joint geometry and machining tolerances.

5. Technological improvement.

These items are all related but will be discussed separately.

\section{Complete Process Control}

GTAW presently used at KCD utilizes either a conventional manual process or a specialized welding system called the "minitig" (originally designed and built at KCD).

In manual GTAW, the operator has hand control of the tungsten welding torch. Sometimes a foot pedal is used to control the welding current during the operation. The process variables of travel speed (TS), torch tip location, arc length (arc voltage, $V$ ), and sometimes arc current (I) are all controlled by the operator. These process variables are related to heat input and weld bead size (including penetration) by the following equations.

$$
H_{n e t}=\text { Net Heat Input }=\frac{f_{1} V I}{T S}
$$

where

$V=$ voltage

1 = current

$\mathrm{TS}=$ travel speed

and

$f_{1}=$ heat transfer efficiency. 


$$
P=\text { Penetration }=K \sqrt[3]{\frac{I^{4}}{T S V^{2}}}
$$

where $K$ is a constant depending on the characteristics of the welding process and includes $f_{1}$ (see references 1 and 2).

These equations are the same whether the process is manual, mini-tig, or fully automatic. In manual welding, the operator has control of all the welding parameters involved in producing an acceptable weld. In mini-tig welding, some of the weld schedule variables, including $X, Y$, and $Z$ motion, are held constant, providing partial process control.

This partial process control provided when using the mini-tig may be eliminated by the engineer, permitting operator override. The variable of torch tip location is usually not overridden during the mini-tig welding process. Still, the operator of the mini-tig must set up the torch tip location (path tracking) before the welding process is started, thus making initial path tracking dependent on machining tolerances and operator accuracy.

Full process control of the welding can only be obtained if arc length, travel speed, torch tip location (path tracking), and current are controlled by a fully automatic system. Below is a list of other processing variables that are set differently from part to part, depending on the results of weld schedule development. In a fully automatic system, these variables are set prior to starting the actual welding process. Failure to correctly set any of these variables could potentially result in an unacceptable weld. A complete list of processing variables can be found in the appendix of this report. All of the following variables (detailed further in the appendix) must be addressed during weld schedule development:
- $\quad$ Current (I)

- $\quad$ Arc Length (AL)

- $\quad$ Arc Voltage (V)

- Travel Speed (TS)

- Cover Gas Type

- Cover Gas Flow Rate

- Electrode Type and Configuration

- Electrode-to-Weld-Joint Position

A fully automatic system should also control the above setup variables, if possible, in order to obtain complete process control.

\section{Weld Joint Geometry and Machining Tolerances}

During the weld schedule development welding coupons were machined at nominal tolerances and weld schedule variables (of a mini-tig system) were set to obtain 0.030 inch average penetration with minimum heat input. Maintaining minimum heat input was critical to avoid burning and charring the foam potting and electrical components located within the housings being welded. The weld schedule was then used in welding the development units. While welding those units, scalloping and incomplete fusion occurred.

After all of the welding variables of the minitig system were carefully studied, it was discovered that the weld joint geometry variations from the piecepart drawings had enough tolerance to cause unacceptable welding conditions. A statistical analysis of the weld joint geometry (weld gap size, flange thickness, flange height, and step size) with an optimized low heat input weld schedule revealed the significant relationship between penetration and the weld joint geometry. This investigation dictated that 
machining tolerances of the components be held extremely tight.

Weld joint geometry range (or the weld joint tolerance range) is affected by both machining tolerances and the outer dimensional requirements of the weldment. The housings used an edge flange weld joint geometry. The weld joint geometry variables are shown in Figure 1. The weld joint geometry range is given from a combination of each piecepart drawing as well as the drawing of the assembly. Figure 2 shows the worst-case analysis of the weldment, indicating a weld joint gap that cannot be closed using the present methods available.

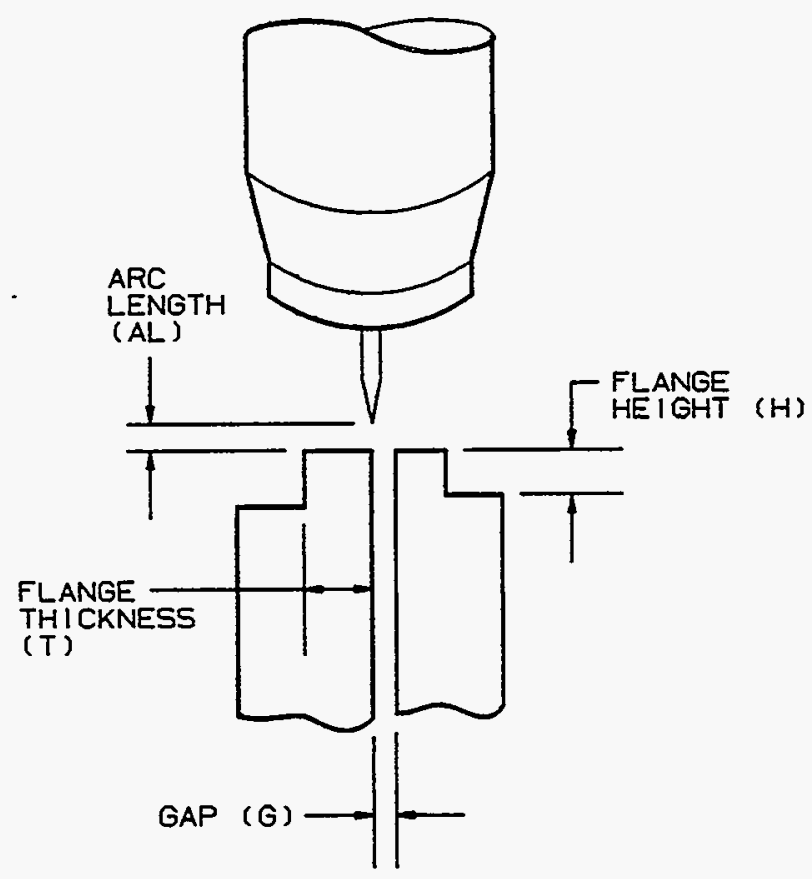

Figure 1. Weld Joint Geometry Variables

It was discovered that the weld joint tolerance range becomes more critical to weld penetration as the weld schedule changes to reduce heat input. The following example explains this concept.

If there are two weld schedules, Schedule A and Schedule B, and
Schedule $A$ has a higher melting efficiency, then Schedule A's penetration will be affected more by a change in weld joint geometry. Schedule $A$ and Schedule $B$ both give 0.030 inches penetration average for nominal parts, but the heat input of Schedule $A$ is less than Schedule B. The weld joint tolerance range will affect the penetration of Schedule A more than that of Schedule B.

Therefore, if minimum heat input is required, machining tolerances must be extremely stringent to maintain a lower weld joint geometry tolerance range. The mini-tig system currently used in production holds the weld schedule variables constant. The proposed fully automatic GTAW system will have feedback process control that will change the weld schedule variables over a range compatible with the weld joint geometry range.

If the weld schedule variables can be changed as the weld joint geometry range changes, then potentially, the weld joint tolerances can be relaxed. This will provide cost savings by minimizing machining time, reducing inspection time, and lowering the cost of nonconformance by reducing scrap and rework.

\section{Path Finding and Tracking}

Also included in the proposed fully automatic GTAW system will be path finding and path tracking capability. Path finding is how a system would locate where to start the welding sequence. Path finding is analogous to the operator setting up a mini-tig to its start location. Path tracking is how a system maintains the torch tip location over the weld joint. Path tracking is analogous to the operator manually following the weld joint during welding. Path finding and path tracking are important because the heat input can be reduced by accurately tracking the weld joint. The ability to both path find 


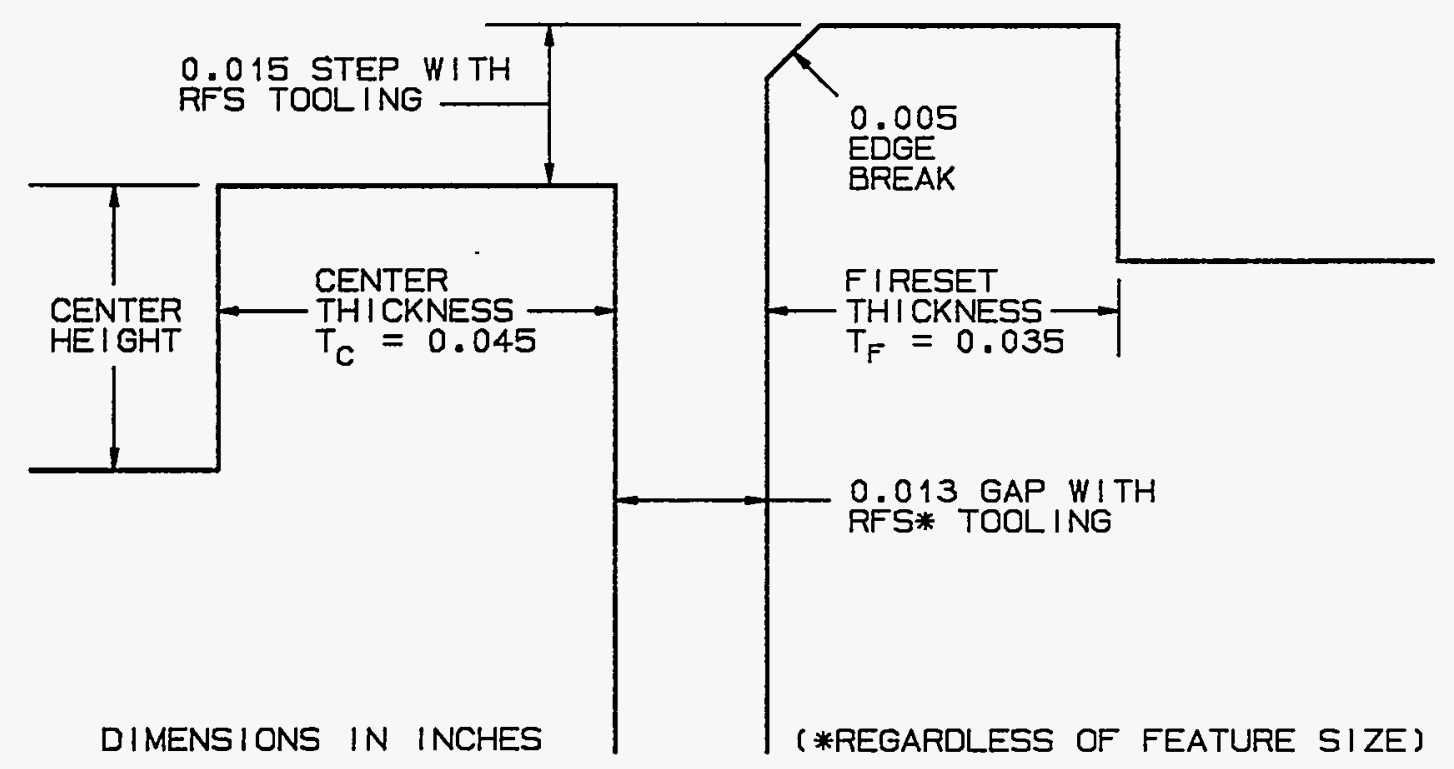

Figure 2. Worst Case of the Weldment

and path track will also reduce tooling costs and operator setup time at the welding operation. Higher production efficiency should also be realized as welding setup time is reduced.

\section{Reduce Risk of Inappropriate Welding}

The electrical and electronic components welded at the KCD have high costs. A fully automatic GTAW system will be programmed to hold certain welding current levels and to maintain adequate travel speeds. This will ensure that the heat input will be below a determined critical value. In addition, the system will have built-in sensors to stop welding before any damage is done. If the risk of damaging electrical and electronic units can be reduced, then a potential associated cost savings can be calculated.

\section{Technological Improvements--Mini-Tig Versus Fully Automatic GTAW}

The mini-tig was developed at the KCD. At its inception it was the state of the art in welding systems for small electrical/ electronic packages. For three reasons, a newer state-of-the-art system needs to be developed:

1. Mini-tig controllers are no longer available,

2. Mini-tigs do not have feedback process control capability, and

3. Three axes of motion might be inadequate for future production and development hardware needs.

The proposed fully automatic GTAW system will have the following benefits over the present mini-tig welding systems.

1. Feedback process control capability.

2. Expandability.

3. Multiple axes and multiple position welding.

4. Both plasma and GTAW capabilities. 
5. Data acquisition system (DAS) output.

6. Permanent visual record of every weld.

7. On-line statistical process control capability (PCC).

\section{Additional Background Information}

Several problems and challenges concerning welding evolve as a result of packing more and more electronics into smaller and lighter packages. These include part tolerance stack-up, thin wall castings, stringent dimensional requirements, hermeticity, and weld penetration requirements. In order to maintain high quality and achieve lower rework, scrap, and production costs, tighter process control must be achieved. The proposed fully automatic GTAW system will increase process control, weld consistency, and weld quality. The welding variables of travel speed, arc length (voltage), current, gap size, and weld joint geometry combine to yield a multidimensional envelope within which a vision-sensing system and its data processing controller will have to operate. The objective is to take proven welding control concepts developed at the design agencies, universities, and other research programs and refine them to a workable process that will operate within the envelope of the welding variables.

Along with in-process control, this visionsensing controlled, fully automatic GTAW system will provide a permanent record of the welding variables critical to the process. A data summary will be automatically generated at the conclusion of each weld which should show that the weld has been completed according to the intended weld schedule.
Automatic GTAW welding was developed at the KCD on two other projects. Neither of these investigations, however, addressed the possibility of in-process feedback control of the GTAW process. During the development work on these two projects, the need for a vision-sensing controlled automatic GTAW system was recognized.

\section{Project Overview}

The activities of this project are presented in the following four groupings:

1. Literature search summary,

2. Vision-sensor torch development,

3. Data acquisition and statistical analysis system development, and

4. ICU producibility investigation.

These four activities are the general framework of this process development project completed to date. The technological aspects of developing a fully automatic GTAW system are extremely diverse, ranging from computer programming and design to optics, laser physics, and statistical analysis.

The objective of this project is to define, design, and develop an automatic GTAW system that has complete process control. The system, when complete, should have the capability to weld any GTAW joint at KCD and have a data report showing that the weld is acceptable.

Two control loops have been identified as mandatory for a successful system. The first is weld schedule variables control, and the second is weld joint tracking control. 


\section{Weld Schedule Variables Control}

In Equation 3 below, the $\mathrm{K}$ factor takes into account all of the variables listed earlier in the "Complete Process Control" section and also the weld joint geometry variables of Figure 1. In order to determine $\mathrm{K}$ and its most significant components, a statistical analysis will be used.

The results will be in the form of a multivariable quadratic equation.

$$
\begin{gathered}
P=K \sqrt[3]{\frac{I^{4}}{T S V^{2}}} \\
K=k(G, T, H, A L, \ldots)
\end{gathered}
$$

The variables of $K$ are separated into two groups according to how they affect the welding process. During the welding process, these variables are either controllable or noncontrollable. This multivariable equation (or the control equation) should determine the controllable variables, given the noncontrollable variables, so that the requirements of the weldment are satisfied. The variables are grouped as shown in Table 1.

The outcome of the statistical analysis will be a set of algorithms that gives values for current (I), arc length (AL), and travel speed (TS), based on the noncontrollable variables of the weld joint geometry. In addition, a predicted penetration value and a predicted temperature value should also be given for the combinations of controllable and noncontrollable variables.

\section{Weld Joint Tracking Control}

In weld joint tracking, the location of the path and the size of the path are controlled by weld joint tolerances to a small degree. However, the location of the path is largely controlled by tooling tolerances, datum locations, and setup positions of the tooling.
Table 1. Weld Schedule Variables

\begin{tabular}{|l|l|}
\hline Controllable & Noncontrollable \\
\hline Current (I) & Gap size \\
\hline Arc length (AL) & Flange thickness \\
\hline Arc voltage (V) & Flange height \\
\hline Travel speed (TS) & Step size \\
\hline Cover gas type & Edge break \\
\hline Cover gas flow rate & Surface condition \\
\hline $\begin{array}{l}\text { Electrode type and } \\
\text { configuration }\end{array}$ & Weld joint location \\
\hline $\begin{array}{l}\text { Electrode to weld } \\
\text { joint position }\end{array}$ & Weld joint path \\
\hline
\end{tabular}

In order to have weld joint tracking control, two activities must occur. First, the path start position must be located. This is called joint finding. Second, the path must then be followed. This is called joint tracking.

In order for an automatic welding machine to find a weld joint, it must have a vision-sensor of some sort. In order to have joint finding capability for all of the GTA weld joints at $K C D$, the system must be able to find the joint in all three directional planes. It has been calculated that the weld joint starting location can be repeated consistently within a 0.5 inch cube range with present tooling concepts, tooling tolerances, and part tolerances. The proposed system will not start the welding sequence until the proper joint path is verified by the vision-sensing system.

Joint tracking in real time can be accomplished by using either of four different methods, depending on welding and optical differences in the parts being welded. The welding differences, such as specification criteria or weld joint geometry, might indicate that one joint tracking method may be preferred over another. Optical characteristics of the weld joint, such as 
reflectivity, may render laser-based tracking unacceptable. Following are the four modes of tracking:

1. Electrode tip to center of weld joint,

2. Electrode tip to center of weld flanges,

3. Weld pool to center of weld joint, and

4. Weld pool to center of weld flanges.

These modes are illustrated in Figure 3.

There are advantages and disadvantages to each mode, depending on the specific application. In order to perform all of KCD's GTA welds, the capability for each will be necessary.

\section{Pre-pass Versus Real Time}

When discussing both weld joint tracking control and weld schedule variables control, a common topic is pre-pass versus real time. Pre-pass means to utilize visionsensing equipment before the arc is ever initiated and store the data in a database, then make decisions of joint tracking changes and weld schedule changes before running the arc welding sequence. Real time means collecting the data, processing it, making changes, and implementing the changes while the arc welding sequence is in progress. The pre-pass method will enable a smaller and slower computer system to complete the feedback control loop; however, if anything changes between the pre-pass and the arc welding sequence conclusion, the result could be a weld failure. Arc gap opening up during welding
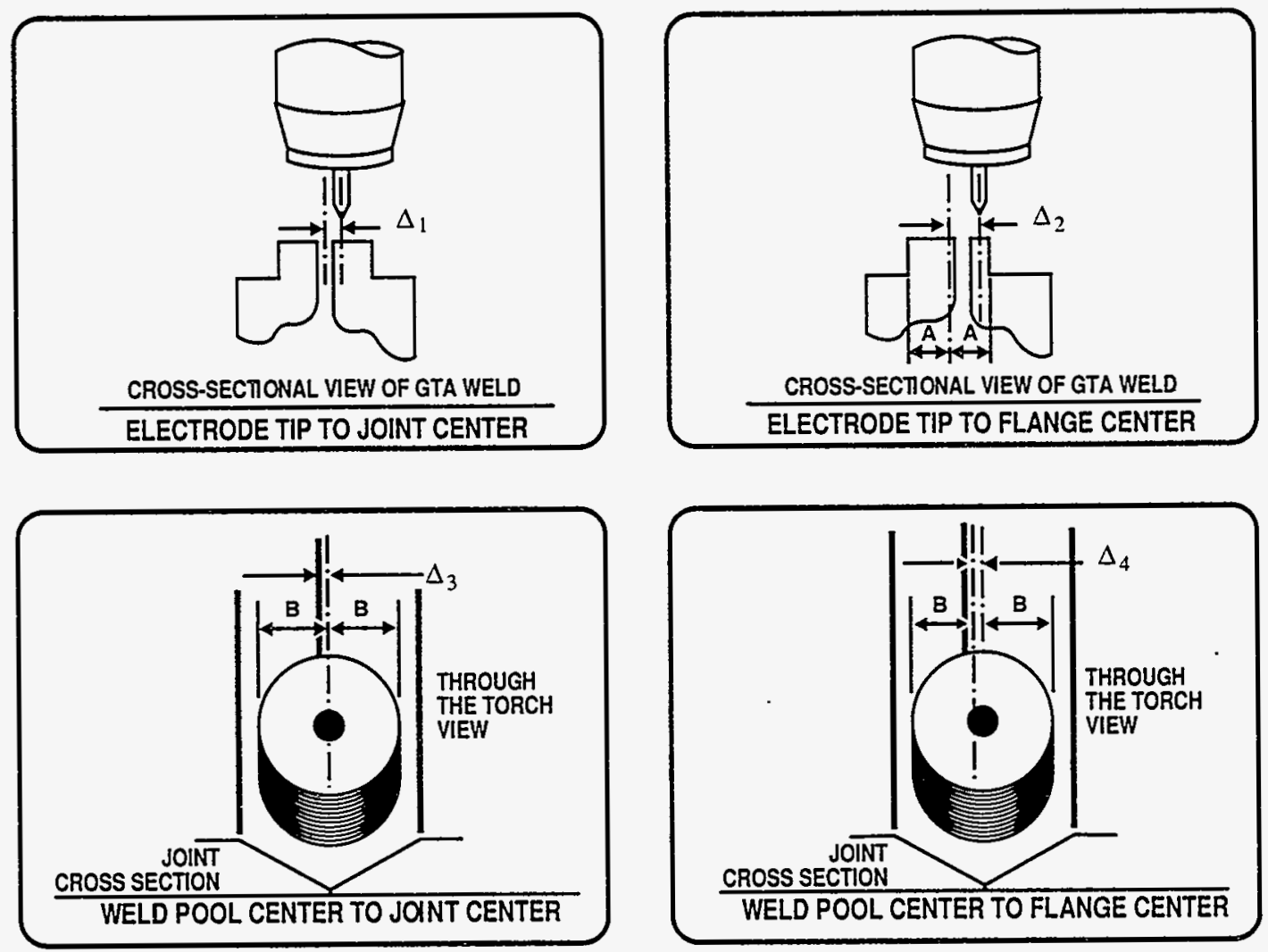

Figure 3. Joint Tracking Four Ways 
is very common. Therefore, it is required that the system be developed for real time operation, the basic justification being that distortion caused by heat input will definitely change the noncontrollable inputs. The KCD system will be designed to provide more information and data to determine the differences between pre-pass versus real time.

\section{Literature Search Summary}

A large variety of weld joint sensor and weld pool sensor technology is available through different universities and development laboratories. Single axis feedback control of path location exists in a few production facilities for GTAW. Thermal models and temperature profile articles are common. Vision processing technology is varied, progressing, and available for real time applications. Reports about the total number and different types of activities involved in GTAW feedback control technologies are presently surfacing.

The literature is inadequate in three areas:

1. Multiple sensor feedback control,

2. Computer programming development, and

3. Pulsed current applications.

The first area includes the use of multiple sensors simultaneously. The second area concerns computer system development and programming. The computer system development for feedback process control is hampered by the variety of computers available, different programming languages, and different buss technologies. In the third area, vision-sensing applications of GTA welding with pulsed current have not been investigated.

For complete process control of all the welds at KCD, only a limited number of options are available. Sensors that are in contact with the work or backside devices would be unacceptable for the electrical products at the KCD. The literature has been carefully reviewed to extract any and all ideas that can be used to benefit a fully automatic GTAW system. Information currently available provides evidence of what will not work and why it will not. Enough information has been accumulated suggesting potential success that development of a system at KCD is possible.

\section{Vision-Sensing Chronology}

To gain an understanding of why multiple sensors will be required and to understand the complexity of computer system requirements, a brief description of how the manual operator uses his or her own senses and what information is gained will be helpful. This is a composite description built from many literature sources. ${ }^{3-6}$ At the end of the literature search section is the explanation of the vision-sensing package chosen. This approach comes from the question of

What does a vision-sensing feedback process control GTAW system need to do?

As the requirements for packaging electrical/electronic components become tougher to attain, the skill level of the manual operator must increase to meet the demand. In order to aid the welding operator, more technology is employed to help produce high quality product. When technology reaches practical limits, the need for more advanced technology arises. To overcome the present limits, the best approach is to reexamine how technology can aid the welding operator.

The manual welder is responsible for coordinating the entire control of the GTAW process. The senses used in manual welding are vision, hearing, and touch. Present sensor and computer technology only addresses one or two of these senses 
and fails to combine them adequately in the way a manual welder does. Table 2 shows all of the senses that a manual GTA welding operator uses, lists the information gained from those senses, and shows how the operator uses this information to produce an acceptable weld. The most important sense is vision, and this is where most of the literature and technological developments have been concentrated for feedback process control.

With a concrete knowledge of what information a manual welding operator is provided with from the natural and unequivocal senses, the approach is usually to determine how to mimic these senses.

From Table 2, it is obvious that vision is the primary information sensor. The literature contains several devices that are vision based or vision oriented. Other devices exist and show up in the literature that utilize different aspects of the setup to gain certain specific information. Almost every device is oriented towards a butt weld joint geometry. Each device needs to be evaluated as it would apply to edge-flange weld joint geometry. Some devices are for gaining backside information. In KCD pieceparts, the backside of the weld joint is usually never accessible. In addition, a qualified welding operator never gets information from the weld joint backside, even when it is available.

From the literature search and in reviewing present technological capabilities, Figure 4 was generated. It is a collective summary of which devices can gain information and an indication of reliability of each device.

Some kinds of information that are needed from the sensor devices are more important than other kinds. At KCD, the castings and sheet metal used for production parts are of high quality, therefore minimizing the need of monitoring unusual events such as blowouts and cold spots. However, joint tracking is very critical because of the weld joint
Table 2. Manual GTAW Process Sensors Information and Use

\begin{tabular}{|c|c|c|}
\hline Sense & Information & Use \\
\hline \multirow[t]{9}{*}{ Vision } & $\begin{array}{l}\text { Locate weld } \\
\text { joint }\end{array}$ & $\begin{array}{l}\text { Maintains weld } \\
\text { on the joint }\end{array}$ \\
\hline & $\begin{array}{l}\text { Monitor torch to } \\
\text { work } \\
\text { orientation }\end{array}$ & $\begin{array}{l}\text { Maintains } \\
\text { proper gas } \\
\text { coverage }\end{array}$ \\
\hline & $\begin{array}{l}\text { Monitor } \\
\text { electrode tip }\end{array}$ & $\begin{array}{l}\text { Tip degradation } \\
\text { will cause weld } \\
\text { characteristic } \\
\text { changes }\end{array}$ \\
\hline & $\begin{array}{l}\text { Monitor are } \\
\text { length }\end{array}$ & $\begin{array}{l}\text { Coordinates } \\
\text { with heat input. } \\
\text { Prevents } \\
\text { electrode } \\
\text { sticking }\end{array}$ \\
\hline & $\begin{array}{l}\text { Monitor weld } \\
\text { pool size }\end{array}$ & $\begin{array}{l}\text { Heat input and } \\
\text { penetration }\end{array}$ \\
\hline & $\begin{array}{l}\text { Monitor heat } \\
\text { pattern outside } \\
\text { the weld pool }\end{array}$ & $\begin{array}{l}\text { Watch for } \\
\text { contamination } \\
\text { burn-off }\end{array}$ \\
\hline & $\begin{array}{l}\text { Monitor fumes } \\
\text { and color }\end{array}$ & $\begin{array}{l}\text { Heat input and } \\
\text { penetration }\end{array}$ \\
\hline & $\begin{array}{l}\text { Monitor weld } \\
\text { pool surface }\end{array}$ & $\begin{array}{l}\text { Watch for } \\
\text { inclusions }\end{array}$ \\
\hline & Unusual events & $\begin{array}{l}\text { Burning, smoke, } \\
\text { etc. indicate } \\
\text { poor weld } \\
\text { quality }\end{array}$ \\
\hline \multirow[t]{3}{*}{ Hearing } & $\begin{array}{l}\text { Intensity } \\
\text { (volume level) }\end{array}$ & $\begin{array}{l}\text { Part-to-part } \\
\text { consistency }\end{array}$ \\
\hline & $\begin{array}{l}\text { Signal (volume } \\
\text { level) } \\
\text { consistency }\end{array}$ & $\begin{array}{l}\text { Same signal for } \\
\text { entire weld }\end{array}$ \\
\hline & Unusual events & $\begin{array}{l}\text { Blowouts and } \\
\text { popping signal } \\
\text { leaks and pin- } \\
\text { holes }\end{array}$ \\
\hline Touch & Heat & $\begin{array}{l}\text { Temperature } \\
\text { control }\end{array}$ \\
\hline
\end{tabular}


Table 2 Continued. Manual GTAW

Process Sensors Information and

Use

\begin{tabular}{|l|l|l|}
\hline Sense & Information & Use \\
\hline Touch & Vibration & Subtle changes \\
\hline Smell & $\begin{array}{l}\text { Normal ozone } \\
\text { smell }\end{array}$ & $\begin{array}{l}\text { Charring or } \\
\text { contamination } \\
\text { burning }\end{array}$ \\
\hline & Intensity & $\begin{array}{l}\text { May not be } \\
\text { perceptible by } \\
\text { odor }\end{array}$ \\
\hline
\end{tabular}

tolerance range and the low heat input weld schedules.

\section{Combine Two Sensors}

This development project will be using two noncontact sensors, a coaxial viewing GTAW torch, and a laser-based triangulation sensor. As Figure 4 indicates, these two sensors compliment each other. The computer system hardware and sottware must be capable of using both sensor devices. Also, the computer system must be capable of adding new sensors as the need arises.

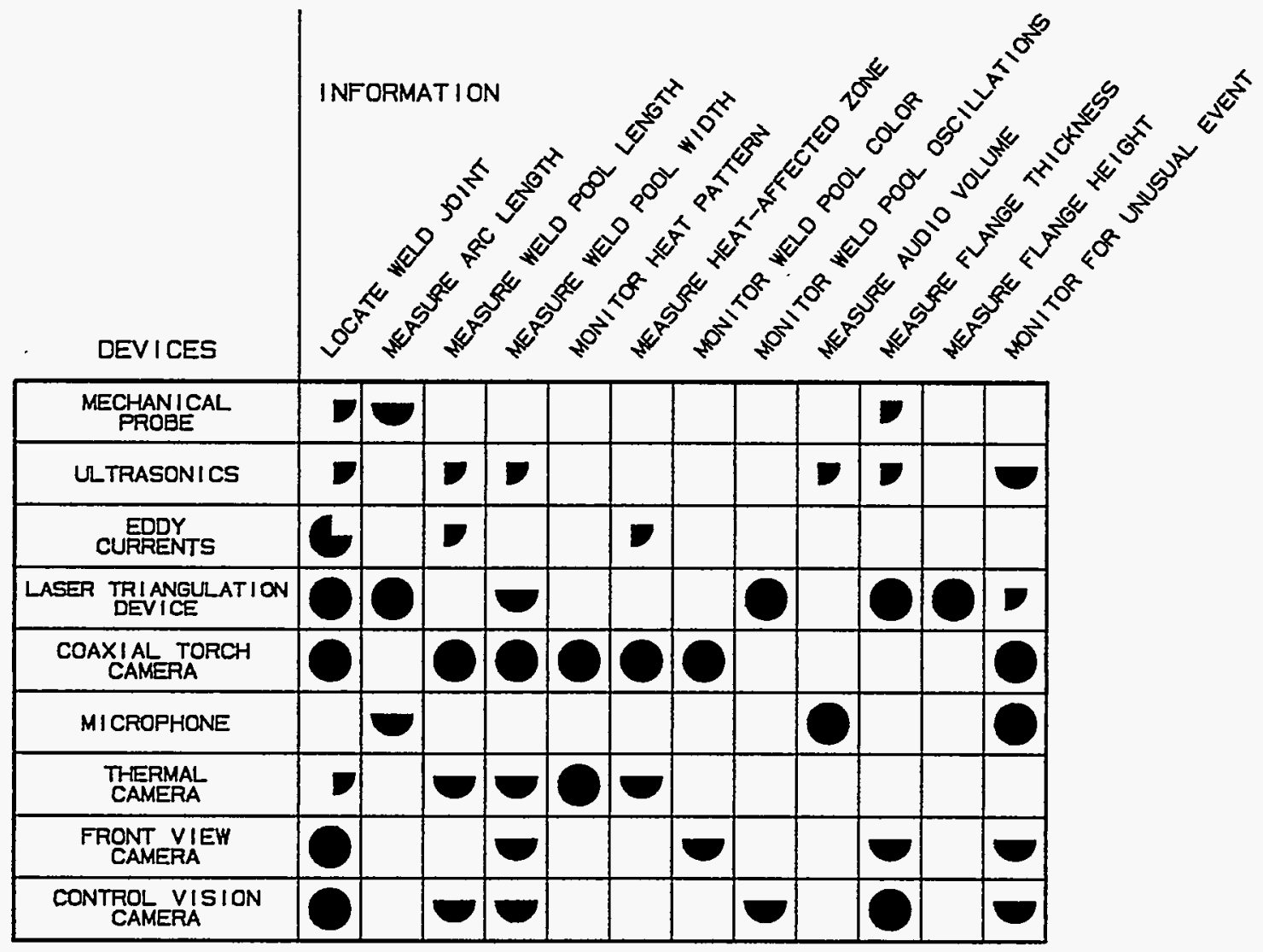

PREDICTED PERCENT USABLE FOR ALL KCD PARTS AND WELD JOINTS

NOTE: NO

BACKSIDE

DEVICES

LISTED

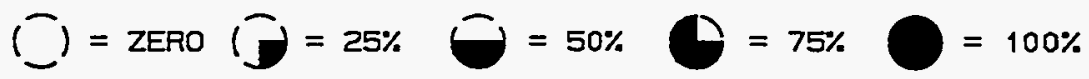

Figure 4. Device Reliability and Information Gained From Each 
In the literature, it was obvious that the leaders in precision GTAW feedback control include DOE production and design agencies, Ohio State University, the United States Navy and a few of their contractors, Colorado School of Mines, and the National Aeronautical and Space Administration (NASA) in Huntsville, AL. NASA has been leading in this field for several years and has published more literature than everyone else combined.

\section{Vision-Sensor Torch Development}

Several ideas and concepts in laboratories and universities have been proven as direct sensors of the GTAW process. Each sensor demonstrates a unique way to detect a single feature of the GTAW process and control a corresponding single process variable. The approach at $K C D$ is to develop a vision-sensor using concepts and ideas that have been proven so that they can be implemented into the KCD manufacturing processes. What resulted was a combination of two sensors which, by establishing algorithms and vision processing, will produce an acceptable weld with a high degree of consistency.

The following is a list of steps taken to determine the present vision-sensing torch design.

1. Review literature (and commercial products) to determine what is possible to detect using today's technology.

2. Determine the requirements of the vision-sensor torch according to KCD experience and experiments.

3. Specify the requirements of a visionsensing torch needed to satisfy these requirements.

4. Incorporate all requirements into a plausible concept.
5. Independently, test each part of the development vision-sensor torch in a cost-effective manor prior to incorporation into a permanent production design.

6. Produce and test the completed production design.

At the time of this writing (fourth quarter of FY90), the project was in the middle of step 5: incorporating and testing the concept.

The literature search summary described a few devices that will detect certain aspects of the GTAW process. These devices cover different techniques that have been proven in laboratories and universities. Some devices required contacting the work piece during welding. Again, this is unacceptable. Every application that has been implemented into a commercial product is basically a single sensor with a single feedback control scenario.

From KCD experience and experiments, several weld joint features that need to be monitored have been determined. The two primary devices needed for detecting these weld joint features are a laser triangulation (measurement) device (LTD) and a coaxial vision torch. A third device--an acoustic monitor (microphone)--might also be required.

\section{Laser Triangulation Device}

The LTD is a structured light sensor which uses a full charge coupling device (CCD) array to send profile information about the weld joint geometry to a vision processor. A schematic of how the structured light sensor works is shown in Figure 5.

The LTD imposes a line of light across the weld joint. A CCD array camera collects the diffuse reflection of this line of light at an angle. The signal is sent to a vision processor and also to a monitor. The vision 


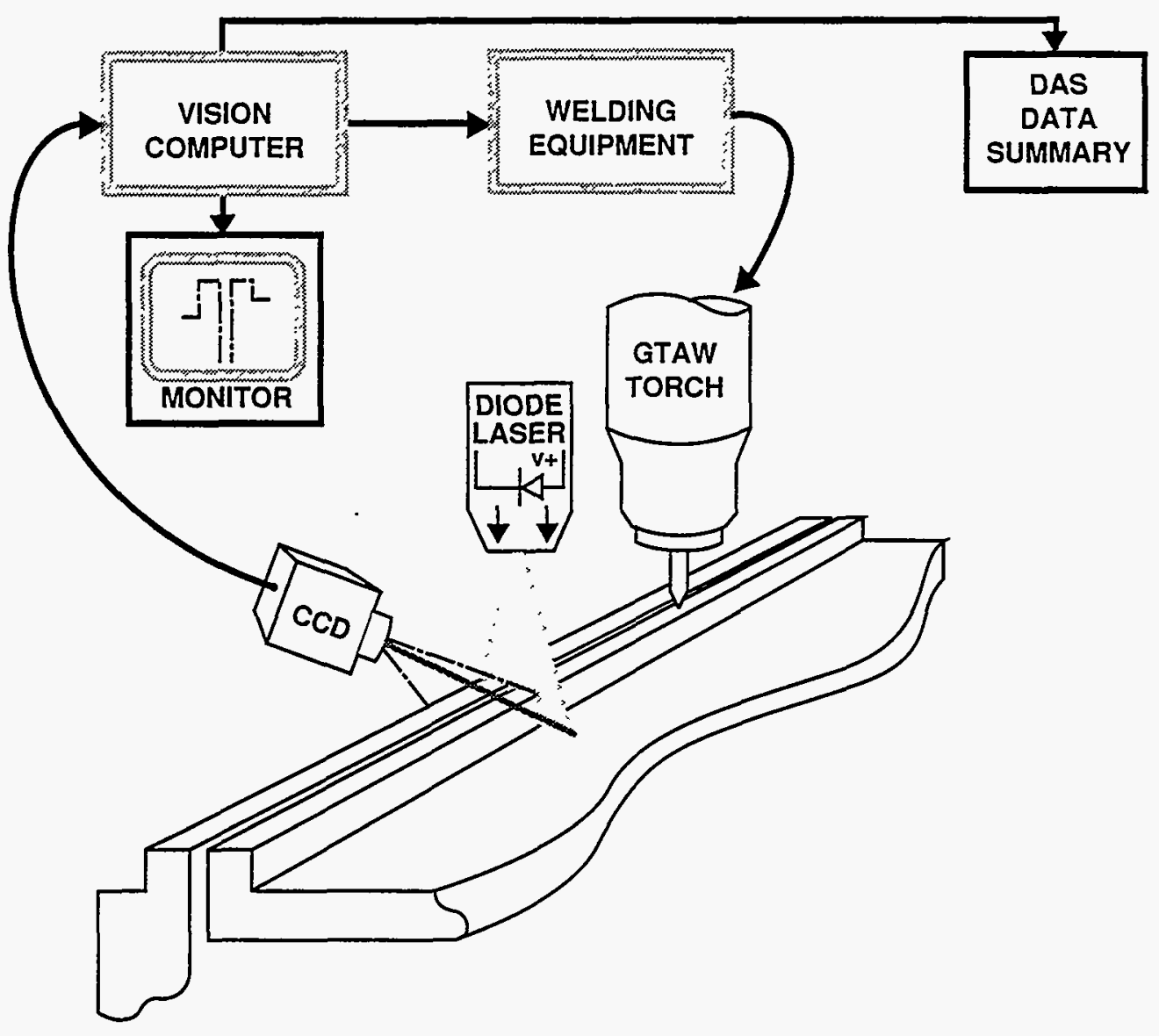

Figure 5. Structured Light Sensor

processor completes vision analysis of the weld joint with various algorithms by using the pixel intensity of the CCD signal. After the vision processor determines pixels or points of interest, the distances that these points represent are calculated. These distances are the size of the gaps, flange height, and other weld joint geometry variables.

Two variables are required for calibration of the measurements: (1) the angle between the line of light and the electrode axis and (2) the distance from the CCD camera to the line of light. With this information programmed into the computer during a calibration exercise, the weld joint geometry variables can be determined with simple geometry equations. The computer will then calculate the welding variable settings that are optimum for the weld joint geometry.
The LTD is also the device of choice to determine the arc length. The arc length is the distance from the electrode tip to the base metal material. As part of the calibration exercise, the distance from the LTD to the electrode tip will also be set in the vision computer memory. This will provide a value from which the computer will be able to maintain arc length control.

The LTD uses a laser diode that operates from about 760 to 800 nanometers wavelength. A narrow band pass filter at the $780 \mathrm{~nm}$ range is used to permit this wave length to reach the CCD array camera. The filter then keeps all other light wavelengths from entering the camera. This filter then blocks the arc light, weld pool light, and other light from giving the camera a complicated image to analyze. By using the filter, the background video noise is eliminated also. Thus, the algorithm used for video image processing is more straight- 
forward and less complicated. The $780 \mathrm{~nm}$ diode is used because there is an opening in the argon arc emittance spectrum at that wavelength. This wavelength opening or window is shown in Figure 6.

\section{Coaxial Viewing Camera}

The coaxial viewing camera is a visible light CCD array camera that is aligned coaxially with the GTAW. electrode. This unique view of the weld process enables a vision-sensing system computer to extract much more information from a GTAW view than an exterior camera could provide. This method of viewing the process also provides a much smaller vision-sensor, which increases access to the weld joint and therefore increases the usefulness of the system. A schematic of this sensor is shown in Figure 7.
Figure 8 shows the development torch now in use in the KCD welding lab. This torch has a fiber optic bundle that brings light for weld joint illumination into a ring illuminator. The development torch also has a standard Linde number 12 gas cup and uses a standard gas/power cable. The 1 inch by 1 inch CCD camera can be seen on top of the lens system. The lens system contains the electronically controlled iris, polarizer, and focus mechanisms.

In Figure 9, the view of the coaxial camera is shown. The blank spot in the center of the photograph is the tungsten electrode. The edge-flange weld joint can be seen both above and below the electrode spot.

Table 3 shows what features need to be detected and the device of choice.

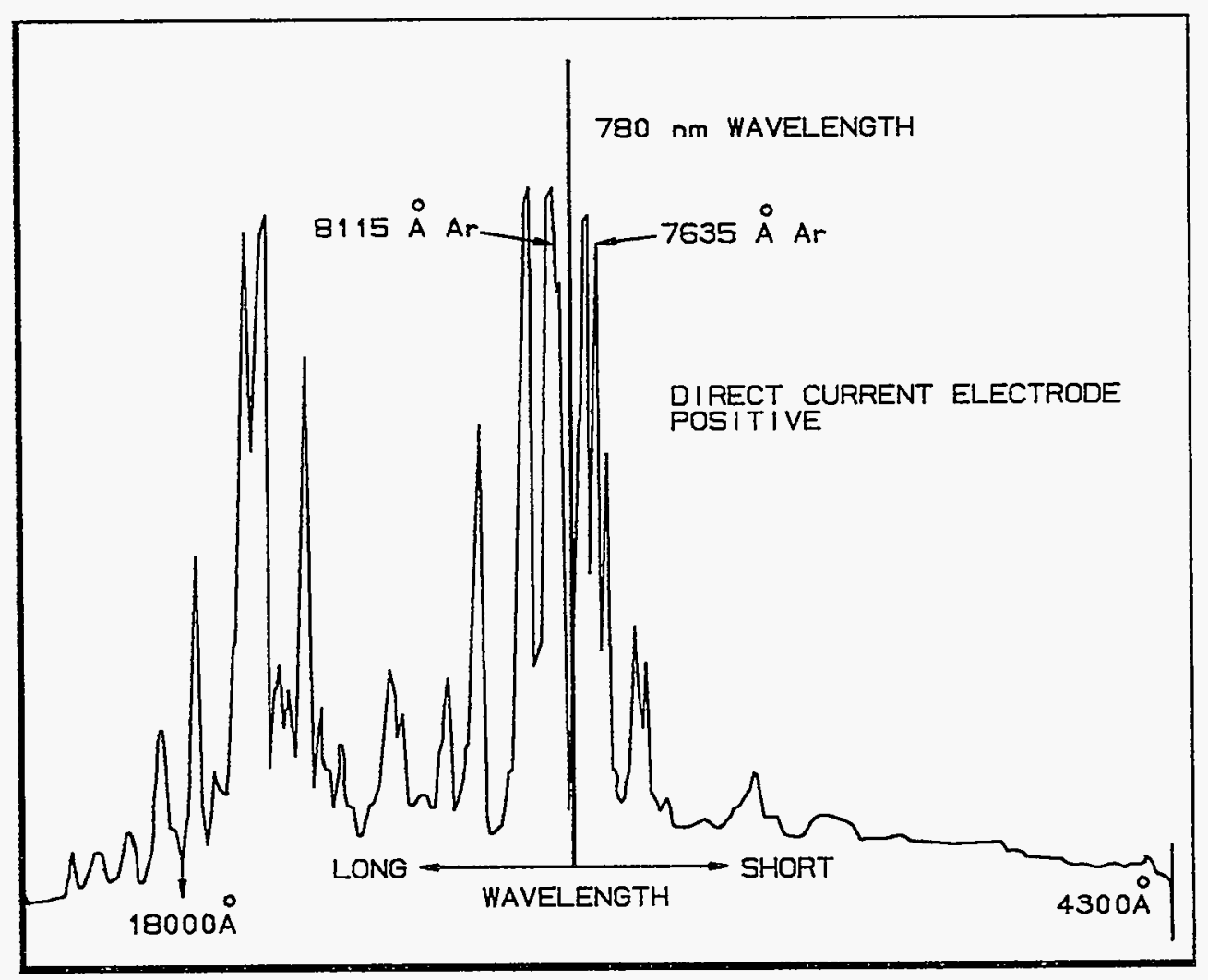

Figure 6. Argon Arc Spectrum Showing the $780 \mathrm{~nm}$ Wavelength Opening 

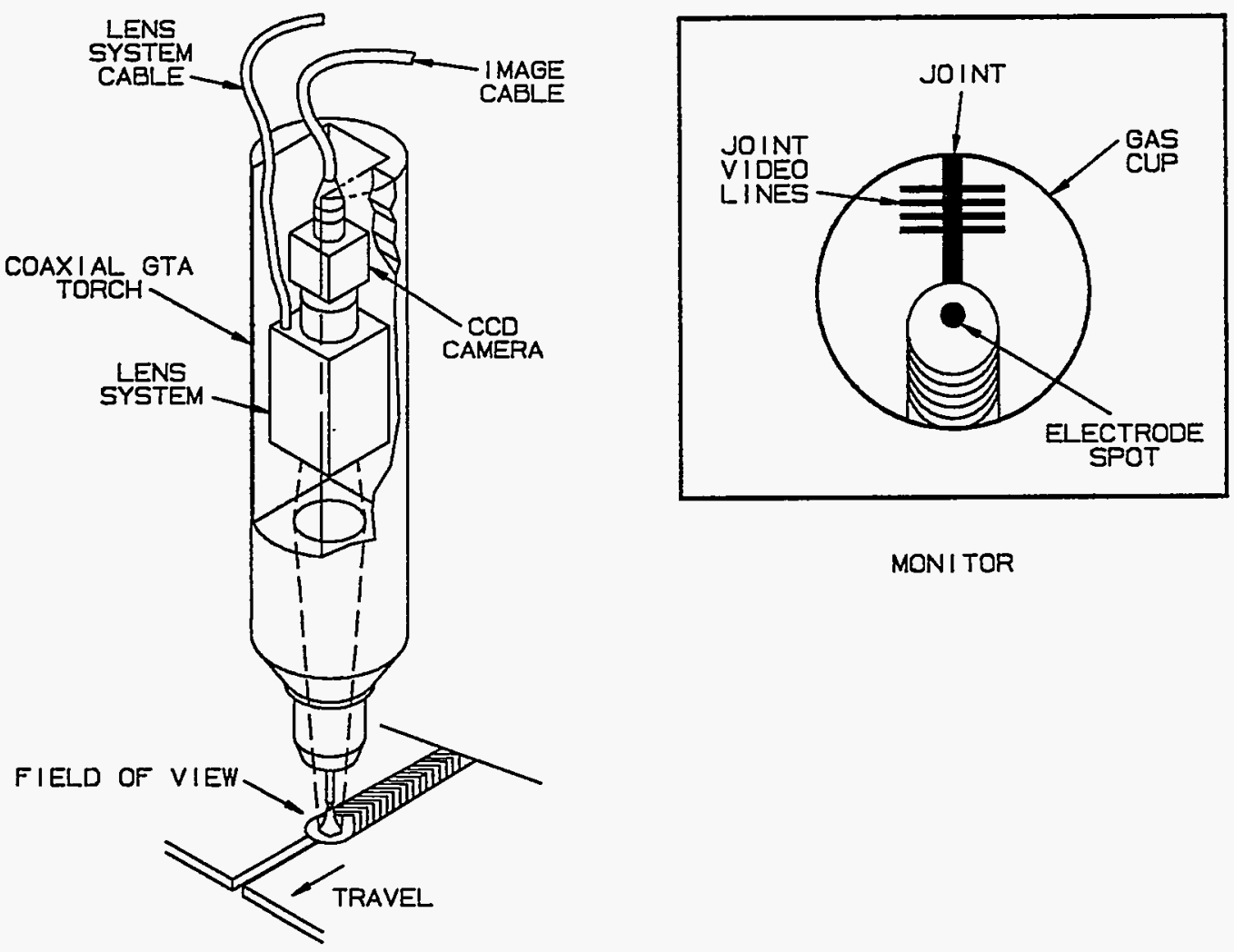

MONI TOR

Figure 7. Coaxial Viewing Camera

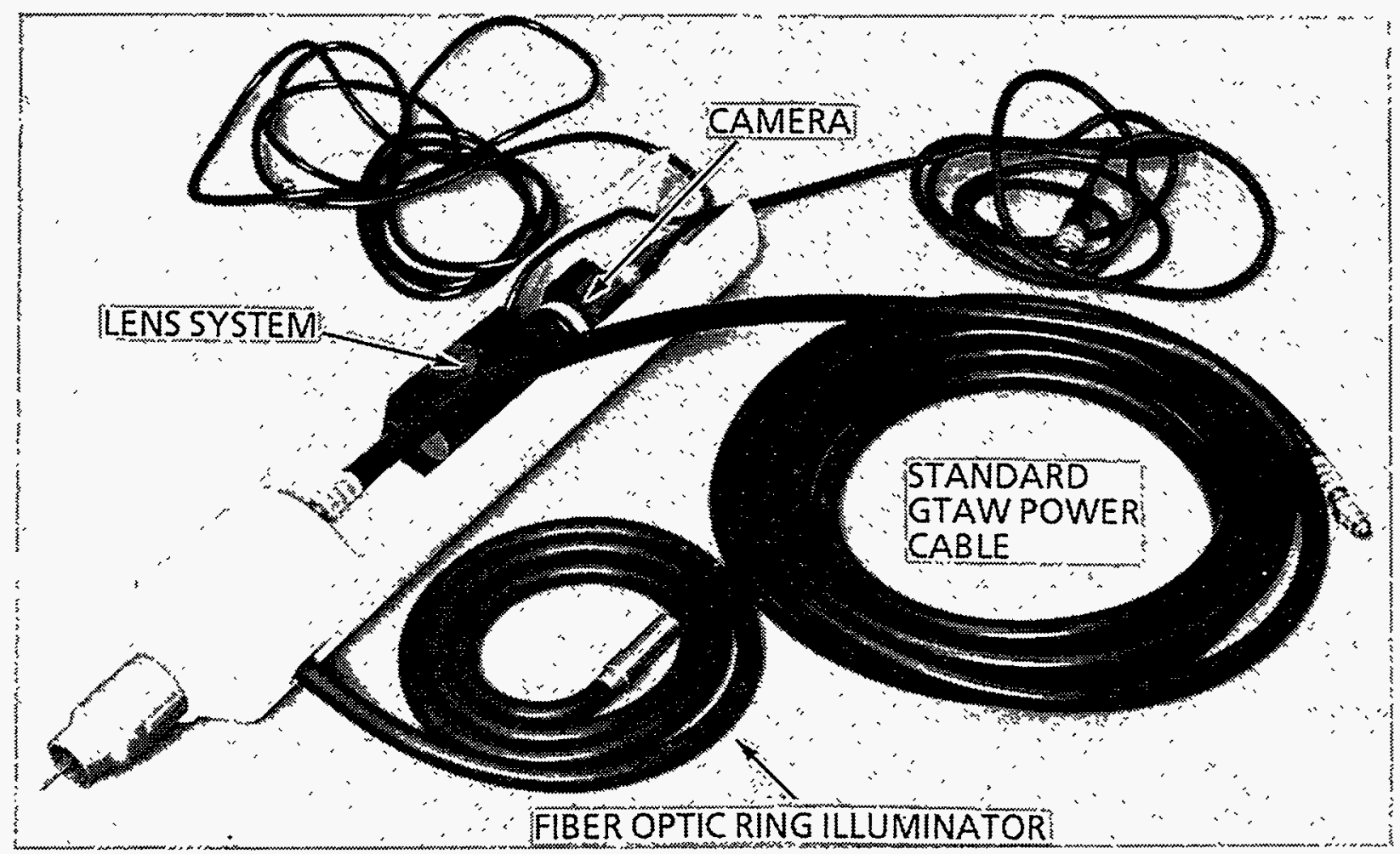

Figure 8. Development Coaxial View Welding Torch 


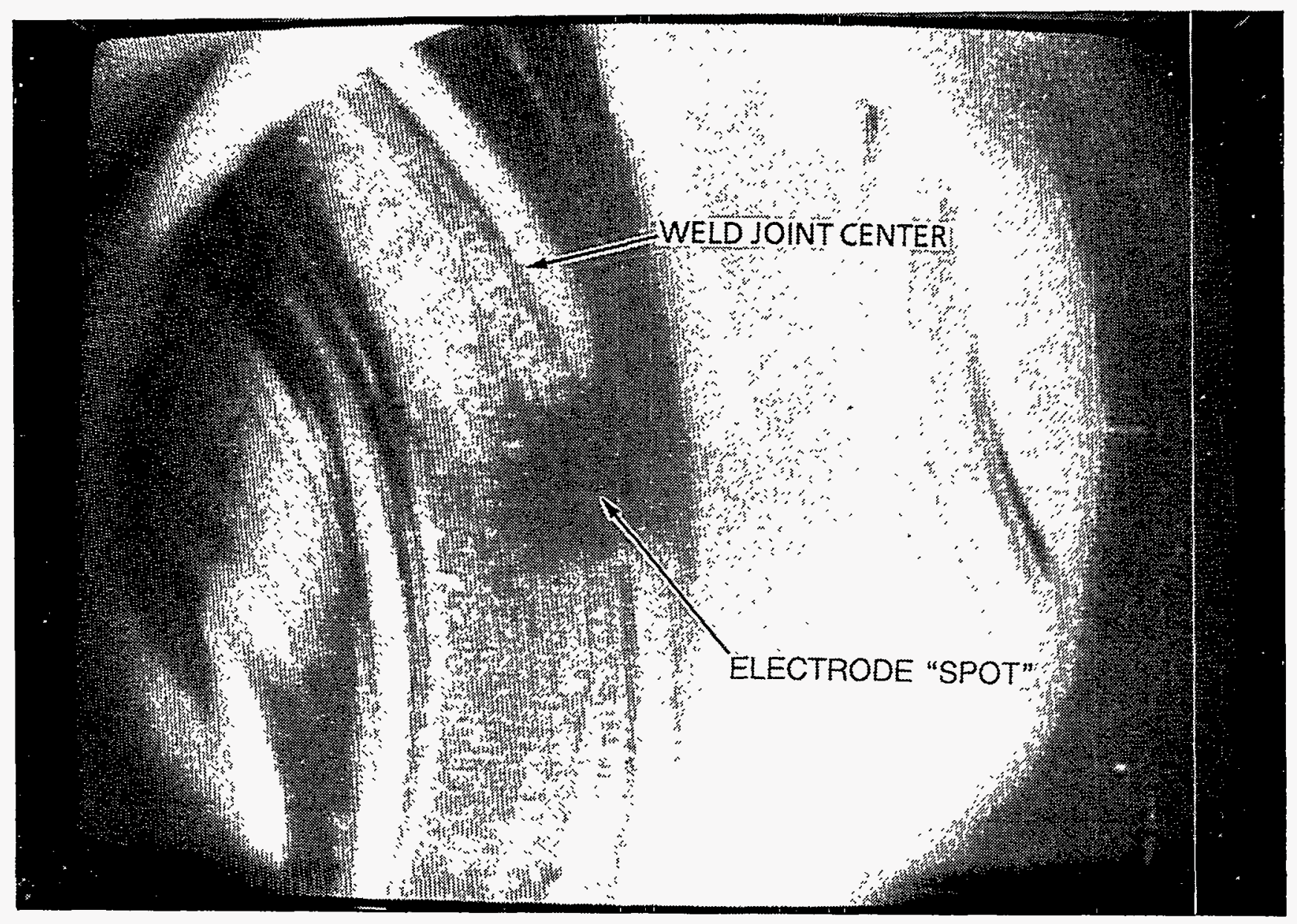

Figure 9. Monitor View From the Coaxial Camera

Table 3. Feature Detected and Device to Use

\begin{tabular}{|c|c|c|}
\hline \multicolumn{2}{|c|}{ Feature Detected } & \multirow{2}{*}{$\begin{array}{l}\text { Device } \\
\begin{array}{l}\text { Coaxial } \\
\text { torch }\end{array}\end{array}$} \\
\hline 1. & $\begin{array}{l}\text { Position location in } \\
\text { the plane } \\
\text { perpendicular to } \\
\text { the torch axis }\end{array}$ & \\
\hline 2. & Arclength & LTD \\
\hline & $\begin{array}{l}\text { Weld joint } \\
\text { geometry }\end{array}$ & LTD \\
\hline & $\begin{array}{l}\text { Weld pool and } \\
\text { surrounding } \\
\text { material }\end{array}$ & $\begin{array}{l}\text { Coaxial } \\
\text { Torch }\end{array}$ \\
\hline & Arc sound & $\begin{array}{l}\text { Miniature } \\
\text { microphone }\end{array}$ \\
\hline
\end{tabular}

\section{Vision-Sensor Combination}

The reasons for choosing these GTAW features are based on experience, experiments, and the need for improved process control. Available information on which weld joint geometry features needed to be monitored for vision-sensing control indicated the need to combine two sensors into one weld torch design.

The positional location of the torch tip in relation to the weld joint changes with different machining tolerances. Also, the path location changes from part to part and with every tool and tooling setup. The LTD cannot identify the weld joint centerline when both the parts have no edge break (the preferred condition), and the parts butt up flat 
against each other. The coaxial torch can detect the weld centerline in this condition.

The arc length is the distance from the tip of the electrode to the closest part of the weld joint. The arc length has a strong relationship with the arc voltage. Arc voltage is one of the major variables of the heat input equation. The laser triangulation device (LTD) is the best and most reliable device to maintain a consistent arc length. However, the arc length control is strongly associated with the weld variables control and, therefore, it may be necessary to include it in the feedback control of the weld variables. This will be determined as the process control equation is developed. Present production methods usually maintain a constant arc length to simplify the application of the process.

The weld joint geometry has several values that must be monitored for reliable feedback process control. These values are gap, flange thickness, flange height, edge break, and step (see Figures 1 and 2). Gap and flange thickness can be best monitored with the coaxial torch. Flange height, edge break, and step can be best monitored with the LTD. Therefore, the vision processing computer needs to be capable of combining and deciphering both sensors, simultaneously at 30 hertz ( 30 hertz is chosen because this is the maximum video processing rate of standard RS170 cameras and frame grabbers).

The information from the weld pool and surrounding material will be used to verify the weld goodness. Several control loops exist that may be implemented, based on weld pool width, weld pool length, width-tolength ratio, and color (both pool color and material color). The KCD system is going to be more proactive and respond to disturbing inputs immediately prior to the welding process rather than reactive, responding to the weld pool size and color. Future work will include a comparison to proactive and reactive process control. The coaxial torch will provide the best method of viewing the weld pool and detecting surface inclusions and incomplete fusion. The color of the surrounding material can also be used as a temperature indicator. Blowouts and nonuniform weld bead observations will be detected, when they occur, and noted in the record of the weld.

Arc sound may provide a signal that the dynamic welding process needs to incorporate into the feedback control loop. An investigation of this aspect will be left for future work. It has been shown in both GTA and laser welding that the through-air acoustic emissions can be used to determine full penetration and arc length/focal point control.

\section{Vision-Sensor Requirements}

The specific requirements of vision-sensor capabilities to satisfy KCD needs are outlined in Table 4. The methodology for determining these requirements was a combination of experience and technical capability. Also included in the requirements for a vision-sensing torch is the accessibility to the weld joint (torch size and shape) and remote electronic control of the focus, iris, and polarizer. Auxiliary external lighting was unacceptable because some of KCD's welded assemblies gave shadows that prevented an acceptable video image. It was also a requirement that the LTD and the vision torch be combined in a single torch design.

The weight of the torch is also critical and must be kept to a minimum for proper interface with the torch manipulator. Most robotic manipulators are limited to less than 10 pounds of weight for the torch. The torch must provide an adequate coaxial view and be capable of a constant current of 100 amperes for a 5 minute length of time (longest electrical products weld at KCD). The LTD must be small and located in the closest acceptable proximity to the electrode 
Table 4. Weld Joint Features and Tolerances

\begin{tabular}{|l|l|l|l|}
\hline & Feature & Range & Tolerance \\
\hline 1. & $\mathrm{~T}_{1}$, thickness of left flange & 0.000 to 0.125 inches & \pm 0.001 \\
\hline 2. & $\mathrm{~T}_{2}$, thickness of right flange & 0.000 to 0.125 inches & \pm 0.001 \\
\hline 3. & $H_{1}$, height of left flange & 0.000 to 0.150 inches & \pm 0.001 \\
\hline 4. & $H_{2}$, height of right flange & 0.000 to 0.150 inches & \pm 0.001 \\
\hline 5. & G, gap between flanges & 0.000 to 0.050 inches & \pm 0.001 \\
\hline 6. & S, step between flanges & 0.005 to 0.150 inches & \pm 0.003 \\
\hline 7. & $E_{1}$, edge break of left flange & 0.001 to 0.040 inches & \pm 0.001 \\
\hline 8. & $E_{2}$, edge break of right flange & 0.001 to 0.040 inches & \pm 0.001 \\
\hline 9. & $\begin{array}{l}D, \text { distance of weld joint } \\
\text { centerline }\end{array}$ & 0.000 to 0.010 inches & \pm 0.001 \\
\hline 10. & AL, arc length & 0.005 to 0.100 inches & \pm 0.001 \\
\hline
\end{tabular}

tip. Table 4 and Figure 10 show the weld joint features and tolerances that will be required from the vision-sensing torch.

\section{Balancing Design Requirements}

In order to incorporate the existing technology, satisfy the technical needs, and have a production design that was easy for the operator to use and practical to implement with production equipment, it was obvious that KCD would need to design and develop a vision-sensing torch. The effort started with a coaxial viewing torch that was developed by Dr. Richard Richardson of Ohio State University. The outer dimensions were downsized, and electronic remote control of the focal distance, iris, and polarizer was added. All wires, tubes, and cables exit the torch at the top to allow for rotating the torch. To the front of the torch will be the LTD, which must be as small as possible for clearance around connector bodies and as close to the electrode tip as possible. Internal coaxial illumination was designed into the torch, which eliminates all undesirable shadows and permits pre-pass and post-welding vision analysis.

The present design is a gas cooled torch that will weld at 100 amperes average current at $50 \%$ duty cycle. The electrode holder is capable of 0.040 inch or 0.062 inch electrodes. The ceramic gas cup is a standard size, and the gas and power connections are the same as standard electrode holders. Below is a specification list containing all data collected to date.

\section{Vision-Sensing Automatic GTAW Torch Specification:}

Diameter: 2.8 inches

Length: 13.5 inches

Weight: 5.2 pounds

Current maximum: 100 amperes average DCEN

Duty cycle: $50 \%$ (a 10 minute test has not been run) 


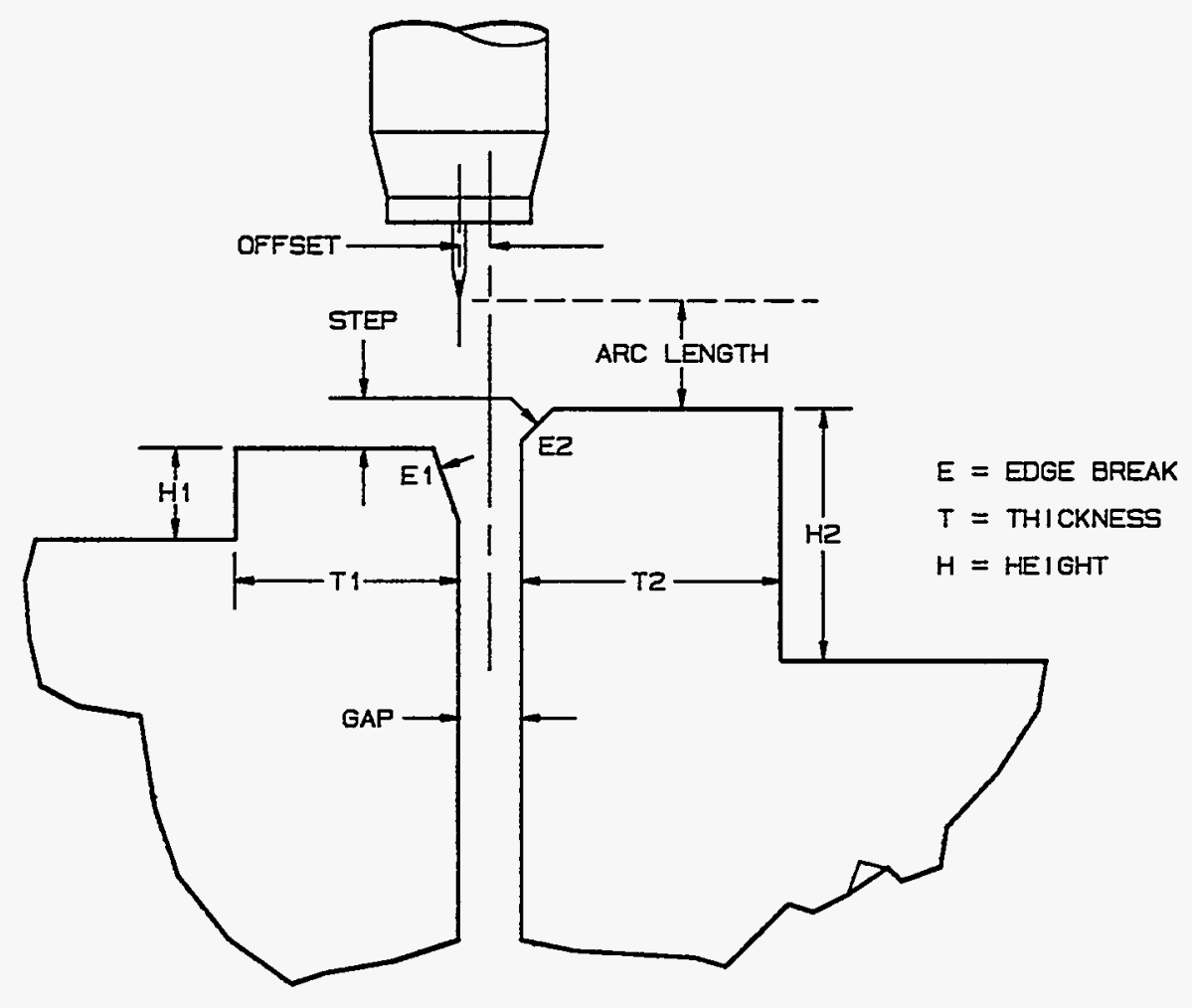

NOTE: THE DIRECTION OF WELDING IS INTO THE PAGE

Figure 10. Weld Joint Cross Section

Diameter view: 0.75 inches

No exterior auxiliary lighting required

Pre-weld and post-weld views obtainable

Ceramic cup size: Weld Craft No. 12 ( 0.75 inch ID minimum)

Recommended electrode length: 3.0 inches

Recommended routine maintenance: change electrode

For reasonable views where a vision processing system is required to make measurements, view to resolution and accuracy are at a ratio of 500 to 1 . This means that if the entire view of the video image is 0.500 inches, accurate measurements will be very reliable down to 0.001 inches.
Data Acquisition and Statistical Analysis System Development

In order to have an automatic GTAW system with feedback process control, the controlling system (computer) must have information (data) and know what to do with the information (programming). This information is obtained with a data acquisition system (DAS). The DAS, after collecting the data, has to use the data for two purposes: (1) to control the process and (2) to verify that the process control is accurate (reporting). These two activities of controlling and reporting are hinged on the same data. The KCD approach is to process the data with a system that can both report and control. Controlling is a real time (during welding) activity, while reporting is a post-weld activity.

Reporting of raw data is simply completed by printing the spreadsheet file. Having a data summary generated is much more beneficial 
than generating raw data. The data summary will have a statistically generated prediction of the pertinent weld joint requirements. The raw data will be stored so that if additional analysis is required, it can be easily input into the computer system.

The welding report should contain the original weld schedule variables and the data summary of the weld. The following information is a minimum expected from the system needed for production.

\section{Controllable Variables Data Summary:}

Programmed Current Range

Average Current

Programmed Peak Current

Average Peak Current

Peak Current Difference

Programmed Background Current

Average Background Current

Background Current Difference

Programmed Arc Length Range

Average Arc Length

Average Arc Voltage

Programmed Travel Speed

Average Travel Speed

\section{Noncontrollable Variables Data Summary:}

Gap Size--Average, Maximum, and Minimum

Flange Thickness--Average, Maximum, and Minimum
Flange Height--Average, Maximum, and Minimum

Step Size--Average, Maximum, and Minimum

Edge Break--Average, Maximum, and Minimum

Surface Condition Oxidation, Sulfur Content, and Foreign Material

Weld Joint Location, Positional Difference From Programmed Location

Weld Joint Path--Size Comparison to Nominal Path, Above or Below

\section{Statistical Weld Joint Requirements Prediction:}

Predicted Average Penetration

Predicted Minimum Penetration

Predicted Maximum Penetration

Predicted Average Peak Temperature at 0.100 inches

Predicted Average Peak Temperature at 0.200 inches

Predicted Average Peak Temperature at 0.300 inches

Acceptable Weld/Unacceptable Weld

The present DAS and control system consists of a Hewlett-Packard (HP) 3852A data acquisition device interfaced with an IBM PSII Model 70 (80386 mother board at $25 \mathrm{MHz}$ ) via National Instruments MC-GPIB (IEEE-488) interface. The HP3852A contains two analog-to-digital high speed voltmeters capable of reading 100,000 readings/second each. These two high speed voltmeters react with a 24 channel high speed FET multiplexer card with thermocouple compensation. 
This DAS system has been hardened for the arc welding environment. Electronic and computer components are vulnerable to electromagnetic radiation interference (EMI) and radio frequency interference (RFI) produced during arc welding.

DOS 4.01 was used as the operating system to integrate standard software packages such as Lotus 1-2-3, dBase III +, LabTech Notebook, Personal Computer Statistical Analysis Software (PCSAS), Turbo Basic, and Turbo $\mathrm{C}++$.

The DAS system was first controlled with a program written in Compiled Basic. The program read current, voltage, and temperature with respect to time from the HP3852A DAS and displayed the results both on the monitor and in Lotus 1-2-3 spreadsheets. Post-weld analysis on the data was done using PC SAS.

Plans are now underway to convert this Basic program to the $\mathrm{C}++$ language. Programs written in the $C$ language will provide faster response times and integration with standard motion control and vision processing libraries.

Two problems concerning the use of the PSII microcomputer and DOS 4.01 were encountered during weld development of the data acquisition and control system. The half card slot space provided by the PSII microcomputer would not accommodate the required full card slot space needed for standard motion control and vision processing boards. In addition, serious real time applications involving process control place heavy demands on the operating system. The operating system needs full multi-tasking capability with task prioritization, efficient inter-task communication, and high speed real time response. DOS 4.01 does not satisfy these requirements.

An Intel 302 development system will soon interface with HP3852A DAS. The $20 \mathrm{MHz}$ 386 microprocessor provides eight standard
ISA I/O slots which will accommodate both the motion control and vision processing boards. Also, this system will include the Intel RMX III real time operating system, in addition to DOS 4.01 . This operating system is typically 100 times faster than genera! purpose operating systems ( 1 to $100 \mu \mathrm{s}$ interrupt times).

The system design goal is to have a complete feedback control loop completed at a rate of $30 \mathrm{~Hz}$. The specific requirement of control rate has not been determined, but $30 \mathrm{~Hz}$ has been chosen for two reasons.

First, when a travel speed of $20 \mathrm{ipm}$ is being run, $30 \mathrm{~Hz}$ gives updates every 0.011 inches. This is calculated as follows:

$$
\begin{aligned}
20 \mathrm{ipm} & =\frac{0.333 \text { inches }}{\text { second }} \times \frac{\text { seconds }}{30 \text { updates }} \\
& =\frac{0.011 \text { inches }}{\text { update }}
\end{aligned}
$$

At $30 \mathrm{ipm}$ an update would occur every 0.016 of an inch. The requirement for update rate could be determined by calculating the largest distance the electrode could travel before an update is necessary.

The second reason is that $30 \mathrm{~Hz}$ is video rate, and vision processing boards are built to handle $30 \mathrm{~Hz}$ data output. This data output, or a video frame, constitutes a refreshed screen. A full frame from both the the LTD and the coaxial camera is taken at $30 \mathrm{~Hz}$. Therefore, a full image can be analyzed at $30 \mathrm{~Hz}$, or once every 0.033 seconds ( 33 milliseconds). This is the fastest rate at which common vision processing boards can analyze a video image because most concerns investigating video processing are using standard $30 \mathrm{~Hz}$ CCD cameras. The cost of a high speed camera ( $60 \mathrm{~Hz}$ or more) is not really justified by what can be gained at this time. 


\section{ICU Producibility Investigation}

This producibility investigation of the Inner Connect Unit (ICU) is based on the potential for utilizing a fully automatic GTAW system with real time feedback control. It is not a producibility rating or producibility investigation in the program related sense. However, obvious producibility benefits of utilizing the fully automatic GTAW system have been identified.

\section{ICU Fabrication}

The ICU consists of four GTA welds which must satisfy minimum penetration requirements of 0.030 inches and pass a hermeticity test of IXIO EE $-5 \mathrm{~cm}^{3}$ per second argon. There are three $304 \mathrm{~L}$ stainless steel hermetic connectors welded into a cold rolled 17.4 ph cover. An edge-flange geometry is machined into the connectors and the cover. The $17-4 \mathrm{ph}$ cold rolled cover is then welded to a machined $17-4 \mathrm{ph}$ investment casting. The weld joint geometry of the cover to the machined casting (housing) is also an edge-flange design. For all GTAW welds, the ratio of flange height to flange thickness is $2: 1$, which is the recommended ratio for proper welding.

Figure 11 shows that the specially designed vision-sensing GTAW torch can access the weld joint between the closely spaced connectors of the ICU.

The connectors are welded into the cover at the start of the ICU assembly. Rigid-flex circuit boards are then placed over the connector pins and soldered into place. Several layers of boards and electrical devices are stacked up on the back of the cover. This entire assembly is then placed into the housing for the cover-to-housing weld. The unit is then leak tested and foam potted, and then a potting plug is laser welded over the potting hole.

The hermetic electrical connectors have heat sensitive glass-to-metal seals, required to keep moisture out of the ICU and prevent corrosion. The thermal shock of welding with too much heat can damage the glass-tometal seals. Warping of the cover with too much welding heat and improper welding sequence will cause stack-up problems for the assembly, as well as weld joint geometry problems at the cover-to-housing weld.

The ICU is similar to past.program ICUs except there are more electronics in a smaller package. An earlier ICU had a 15\% reduction in leak test failures after adding copper chills to the glass-to-metal seals. This demonstrates that heat sensitivity problems will need to be addressed. The proposed system should completely eliminate all heat-related leak test failures.

The earlier ICU cover-to-housing weld is extremely operator dependent. Currently, the operator is controlling the percent feed rate override (the welding travel speed) of a minitig system. This has led to some units being scrapped because of over-welding. The design of the latest ICU will not be as vulnerable to over-welding because the machining operations will be less difficult on the rectangular design.

An additional benefit of the new fully automatic GTAW system will be proper cover gas shielding. Not only will the electrode have proper argon shielding, but the weld pool and surrounding base metal will also be shielded with argon cover gas in order to prevent surface oxidation and weld pool contamination.

\section{Weld Joint Geometry}

The weld joint geometry for the three connector welds as well as the cover-tohousing weld has a flange height to flange thickness ratio of 2:1.

A weld schedule will be set for the first development units using worst-case coupons, according to normal engineering 


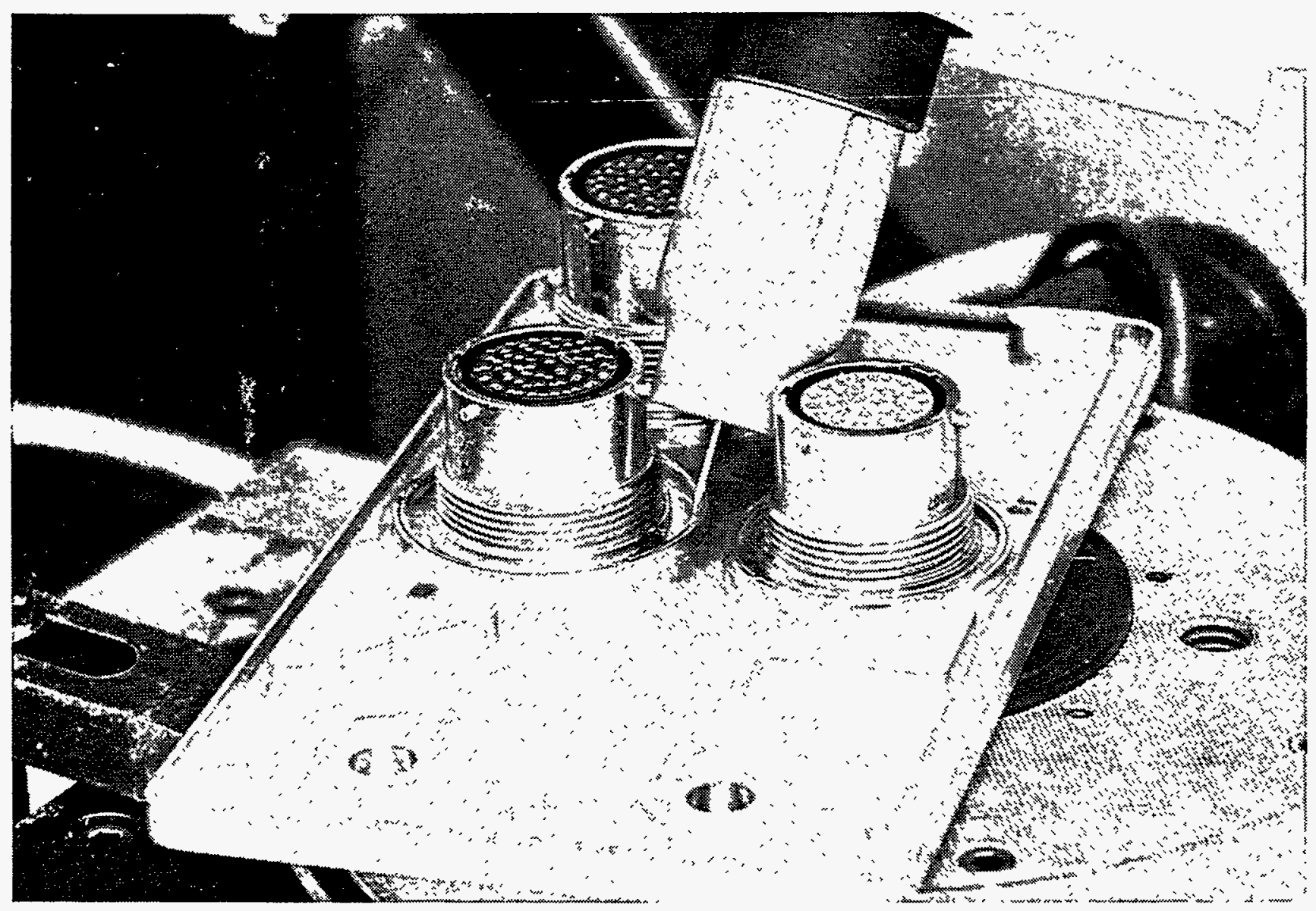

Figure 11. ICU Connectors and Cover With Welding Torch

practices. These first units will be thermocoupled for temperature data. The welding travel speed will be set at 35 to $45 \mathrm{ipm}$, as recommended by Sandia National Laboratory, Albuquerque. This high travel speed is considered the best for low heat input and high melting efficiency. (Melting efficiency is defined here as the amount of heat necessary to just melt the fusion zone, divided by the net heat input to the part. This definition is from an SNL, Albuquerque welding investigation. ${ }^{7}$ ) At this high travel speed, equal to two times higher than any other weld at KCD, operator override of any kind would be difficult.

The increased travel speed will make it almost impossible for operator control of any welding parameter during welding. There are two reasons for this. First, the faster the travel speed, the faster the operator will have to react to the welding parameters being controlled. Second, the weld joint geometry becomes less forgiving as the welding process becomes more efficient. Therefore, the welding operator must be not only faster but also much more accurate. For these reasons, this faster travel speed recommendation can only be accommodated with a fully automatic GTAW system.

\section{Accessing the Weld Joints}

The three connectors, as shown in Figure 11, have no room between them for the smallest standard gas shielding ceramic cup. In order to access the weld joint and provide proper shielding, two methods of GTAW process variations are being investigated. Both methods are being evaluated to determine which method gives the best process control. 


\section{Method 1:}

Using a standard ceramic gas cup, (number 12) to provide shielding: An electrode extension of 0.6 inches is used, with the torch held at a $45^{\circ}$ angle from vertical. The torch is then moved around the connectors, shielding the electrode and the weld pool.

\section{Method 2:}

Using no gas cup, but instead, an argon dam: A bare electrode has an unprotected extension of 1.7 inches. The argon dam is 4 inches high. The torch is not held at an angle but remains normal to the weld joint plane.

Programming the weld path is more straightforward.

Method 1 has been proven to provide excellent shielding to the weld pool, the electrode, and the surrounding base metal material.

Method 2 has not yet been tested for adequate argon shielding. However, if the argon dam method fails, it might be possible to use a shielding bag or even a glove box arrangement.

The pros and cons of both methods are shown in Table 5.

\section{Obtaining Noncontrollable Variables Data}

The noncontrollable variables data for the ICU will be obtained from the combination coaxial torch and laser triangulation device described earlier. The disturbing inputs data can be obtained from each of the preceding gas shielding methods. Method 1 will require the vision sensing system to calibrate a $45^{\circ}$ angle into the vision-sensor processing. The torch will be required to rotate continuously for Method 2, whereas for Method 1, torch rotation will be segmented,
Table 5. Gas Shielding Methods

\begin{tabular}{|c|c|}
\hline $\begin{array}{l}\text { Method 1: } \\
\text { Typical shielding } \\
\text { technique with an } \\
\text { angled torch }\end{array}$ & $\begin{array}{l}\text { Method 2: } \\
\text { Untypical shielding } \\
\text { technique with torch } \\
\text { perpendicular to } \\
\text { weld joint }\end{array}$ \\
\hline $\begin{array}{l}\text { 1. Pro: Normal } \\
\text { gas shielding } \\
\text { method }\end{array}$ & $\begin{array}{l}\text { 1. Pro: Easy to } \\
\text { program part } \\
\text { path }\end{array}$ \\
\hline $\begin{array}{l}\text { 2. Pro: No } \\
\text { auxiliary } \\
\text { shielding }\end{array}$ & $\begin{array}{l}\text { 2. Con: Requires } \\
\text { additional } \\
\text { shielding gas } \\
\text { arrangement }\end{array}$ \\
\hline $\begin{array}{l}\text { 3. Pro: Proven } \\
\text { that shielding } \\
\text { is adequate }\end{array}$ & $\begin{array}{l}\text { 3. Con: Shielding } \\
\text { method not } \\
\text { proven yet }\end{array}$ \\
\hline $\begin{array}{l}\text { 4. Pro: view of } \\
\text { weld joint is } \\
\text { acceptable }\end{array}$ & $\begin{array}{l}\text { 4. Pro: View of } \\
\text { weld joint is } \\
\text { acceptable }\end{array}$ \\
\hline $\begin{array}{l}\text { 5. Con: View of } \\
\text { weld joint is } \\
\text { on a } 45^{\circ} \text { angle } \\
\text { and will } \\
\text { require } \\
\text { additional } \\
\text { vision } \\
\text { processing }\end{array}$ & $\begin{array}{l}\text { 5. Pro: View of } \\
\text { weld joint is } \\
\text { normal to part } \\
\text { path }\end{array}$ \\
\hline $\begin{array}{l}\text { 6. Pro: No } \\
\text { additional } \\
\text { tooling } \\
\text { required }\end{array}$ & $\begin{array}{l}\text { 6. Con: } \\
\text { Additional } \\
\text { tooling or } \\
\text { glovebox } \\
\text { required }\end{array}$ \\
\hline
\end{tabular}

with the smaller moves around the connectors.

\section{Completing the Process Control Loop}

A process control loop for either positional location or welding parameters can be completed by referencing a known database $(\mathrm{KDB})$ or by algorithm calculation (AC). KDB control is completed by taking the values of the disturbing inputs and finding corresponding welding parameters from a 
table or database of known signals that has been previously determined. AC control is completed by taking the values of the disturbing inputs and calculating the corresponding welding parameters from equations previously formulated. It is also possible to use a combination of KDB and AC.

\section{Accomplishments}

The ICU GTAW technical feasibility has been proven.

Coaxial illumination of a coaxially viewing GTAW torch has been implemented and shows excellent welding views as well as pre- and post-weld joint views.

The DAS has been hardened for the GTAW environment and is capable of accepting a trigger signal from the mini-tig to start the collection of data.

\section{Future Work}

The following efforts are planned for the present GTAW project.

1. Continue with current plans to develop feedback control and vision processing with an Intel 302 development system.

2. Integrate the GTAW torch design to include both coaxial viewing and laser triangulation structured light view. Finalize the design for a production definition.

3. Increase the DAS acquisition rate to $30 \mathrm{~Hz}$ for at least 18 thermocouple channels and for all other variables such as current, voltage, and travel speed.

4. Convert DAS programming language from Basic to $C$.
5. Develop a rotating torch capability for the mini-tig/dabber welding system.

6. Finalize programming and format for a DAS data summary at the end of each weld (including process variables as well as production control information; that is, $P / N, S / N$, weld joint, date, etc.).

7. Develop a vision-sensing computer calibration procedure.

8. Implement video annotation of weiding parameters.

Future projects will include the following work.

1. Develop a menu-driven DAS.

2. Implement programming of a feedback control for wire feeding into the GTAW process.

3. Establish process control statistical equations for other MCs.

4. Implement the vision computer system to use bar codes of products and tools. 


\section{References}

'American Welding Society (AWS), Welding Handbook. Vol. 1, 7th Edition, Chapter 2. p 36.

${ }^{2}$ C. E. Jackson and A. E. Shrubsall, "Control of Penetration and Melting Ratio with Welding Technique." Welding Journal, April 1953.

${ }^{3}$ Project No. J6084, Edison Welding Institute, Columbus, $\mathrm{OH}$.

Interim Reports:

Number J6084-88-4, "Evaluation of Sensor and Control Technologies."

Number J6084-88-5, Revision 1, "Evaluation of the Oldelft Seampilot Sensor."

Number J6084-89-8, "Evaluation of the Control Vision Strobed Laser Illumination System."

Number J6084-89-10, "Evaluation of the Modular Vision System Laser Vision Sensor."

Number J6084-89-11, "Repeatability, Overshoot and Accuracy Test on the Ferranti Sciaky Acuweld 500 System."

Number J6084-89-9, "Review of Commercial Video Image-Processing Systems."

${ }^{4}$ Richard W. Richardson, A Vision-Based Adaptive GTA Welding System for Aerospace Applications. (Research Report). Ref. MR 8702, Edison Welding Institute, Columbus, OH, September 1986.

${ }^{5}$ R. Bruce Madigan and Harvey R. Castner, Survey of Weld-Penetration Control

Techniques (Research Report). Ref. MR 9002, Edison Welding Institute, Columbus, $\mathrm{OH}$, January 1990.

${ }^{6}$ S. J. Marburger, Optical and Electronic Methods for Weld Arc Viewing (Sandia Report). Sandia National Laboratory, Albuquerque, NM, and Livermore, CA, April 1984.

${ }^{7}$ P. W. Fuerschbach, Melting Efficiency in Fusion Welding. Sandia National Laboratory (Sandia Report). Albuquerque, NM, September 1991. 


\section{Appendix}

\section{Main Input Variables}




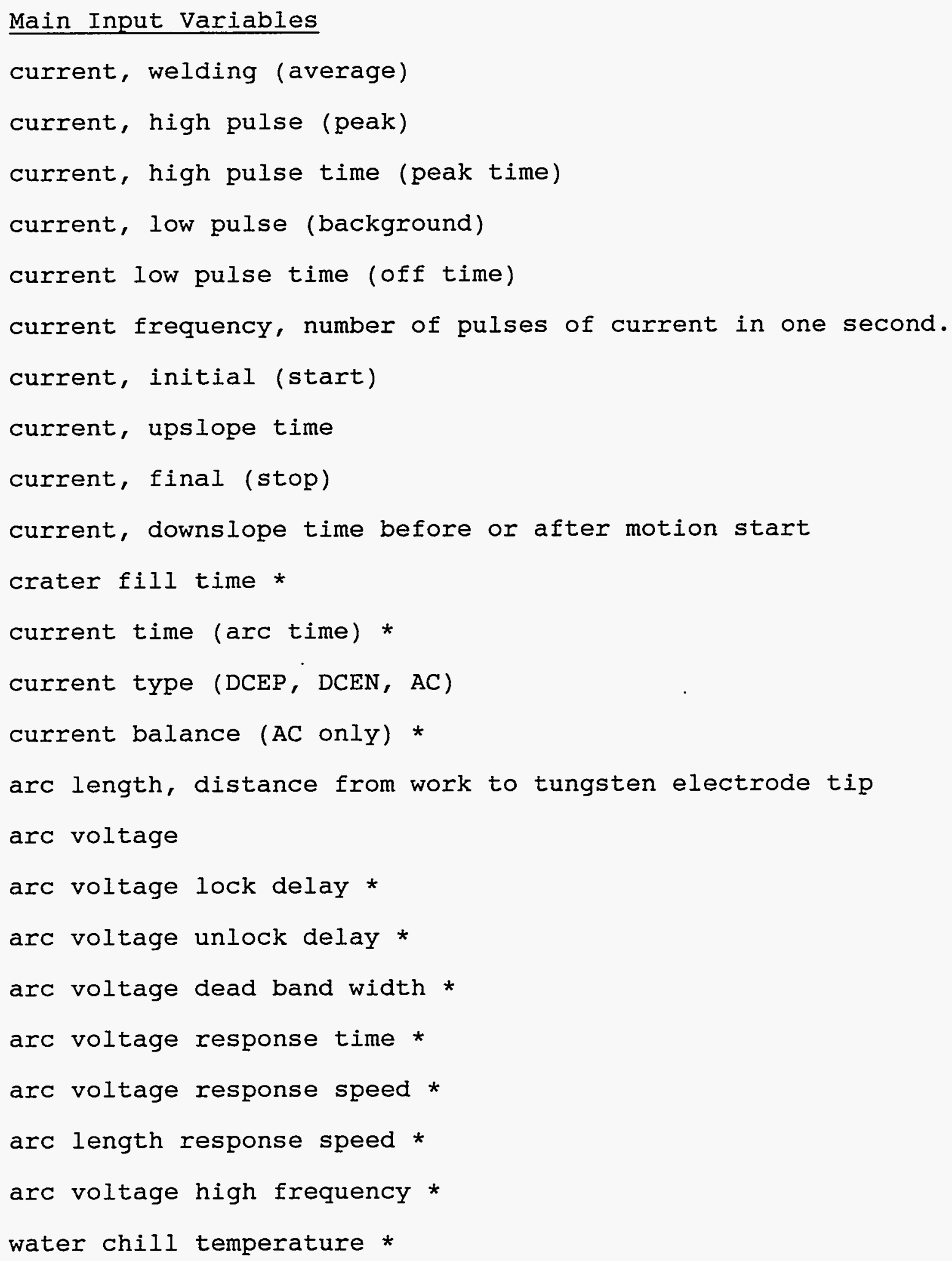




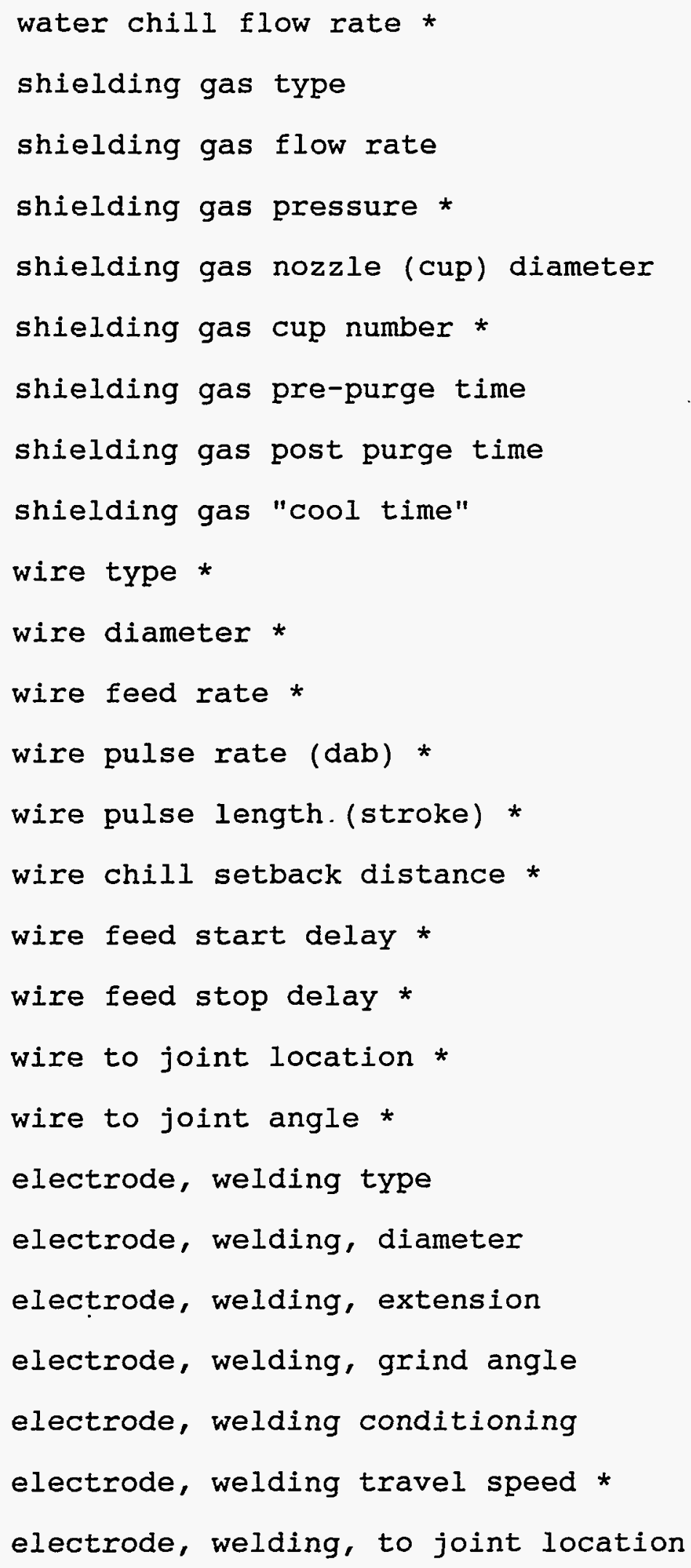


electrode, welding, pattern NNN *

electrode, welding, dwell; the time delay before the electrode moves after arc is established

electrode, welding, to work angle (travel, work, drag) * electrode, welding, setback (plasma) *

electrode, welding, to joint position (flat)

safety interlocks closed

base metal type

Joint tracking method ( 1 of 4 )

preheat temperature *

Disturbing Input Variables

weld joint geometry, cross-sectional features of a weld joint

before welding

thickness (2), see Figure

gap, see Figure

height (2), see Figure

step see Figure

edge break (2), see Figure

heat sink mass *

bevel angle *

grove angle *

surface conditions, surface pre-weld activities cast *

ground *

machined *

rusted * 


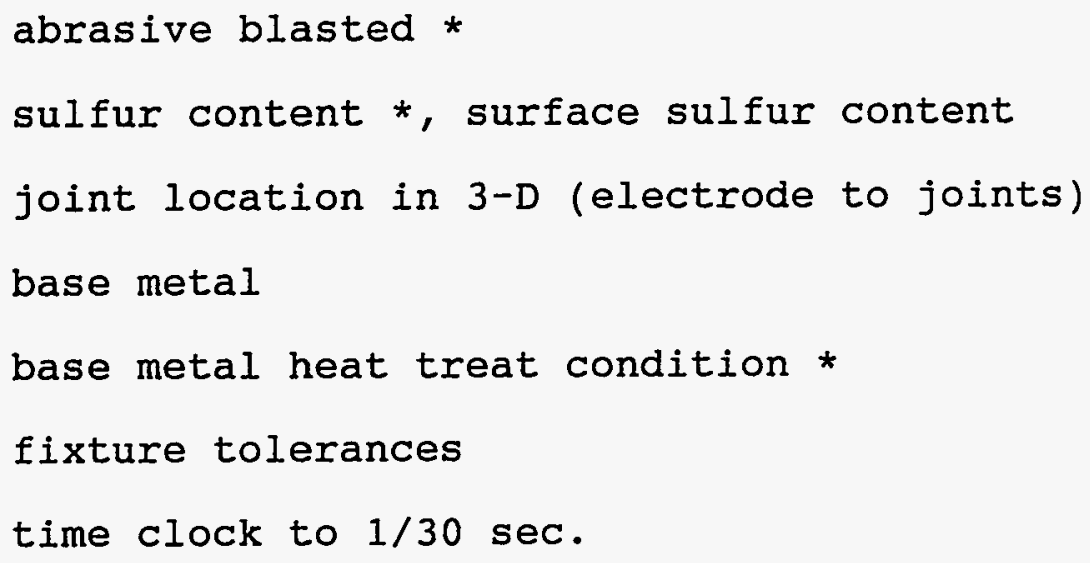

BKSP / 13 